\title{
Modification of Azobenzenes by Cross-Coupling Reactions
}

\author{
Melanie Walther ${ }^{\mathrm{a}, \mathrm{b}}$ (D) \\ Waldemar Kipke ${ }^{a, b}$ (D) \\ Sven Schultzke ${ }^{a, b}$ (iD) \\ Souvik Ghosha,b (iD \\ Anne Staubitz*a,b (iD) \\ a University of Bremen, Institute for Analytical and Organic \\ Chemistry, Leobener Straße 7, 28359 Bremen, Germany \\ staubitz@uni-bremen.de \\ b MAPEX Center for Materials and Processes, Bibliothekstraße 1, \\ 28359 Bremen, Germany
}

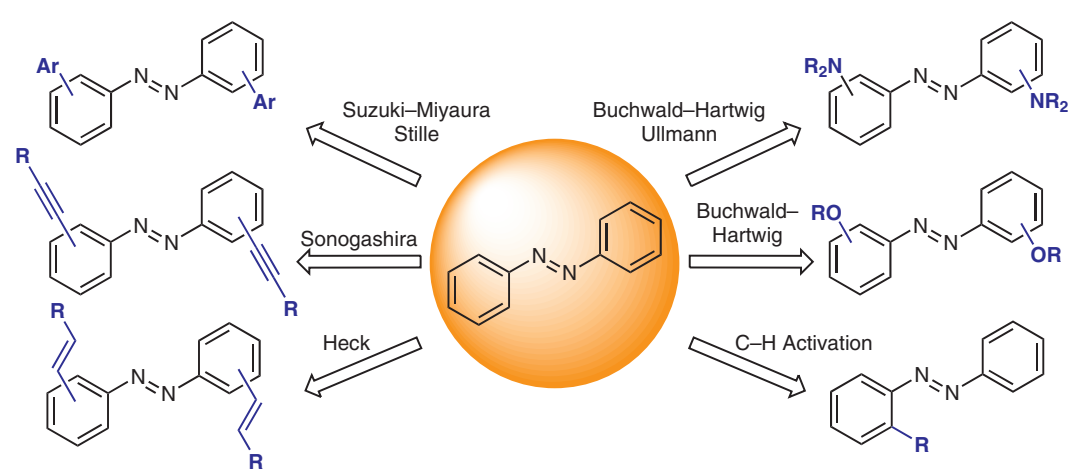

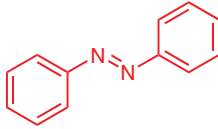

$($ (日)

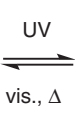

vis., $\Delta$

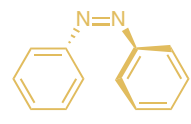

$(Z)$

(c) 2021. The Author(s). This is an open access article published by Thieme under the terms of the Creative Commons Attribution License, permitting unrestricted use, distribution and reproduction, so long as the original work is properly cited. (https://creativecommons.org/licenses/by/4.0/)

\begin{tabular}{|c|c|}
\hline \\
\hline \multicolumn{2}{|r|}{$\begin{array}{l}\text { Abstract Azobenzenes are among the most extensively used molec- } \\
\text { ular switches for many different applications. The need to tailor them to } \\
\text { the required task often requires further functionalization. Cross-cou- } \\
\text { pling reactions are ideally suited for late-stage modifications. This re- } \\
\text { view provides an overview of recent developments in the modification } \\
\text { of azobenzene and its derivatives by cross-coupling reactions. } \\
1 \quad \text { Introduction }\end{array}$} \\
\hline \\
\hline \multicolumn{2}{|r|}{$2 \quad$ Azobenzenes as Formally Electrophilic Components } \\
\hline 2.2 & Nickel Catalysis \\
\hline 2.3 & Copper Catalysis \\
\hline 2.4 & Cobalt Catalysis \\
\hline 3 & Azobenzenes as Formally Nucleophilic Components \\
\hline 3.1 & Palladium Catalysis \\
\hline 3.2 & Copper Catalysis \\
\hline 3.3 & C-H Activation Reactions \\
\hline & Azobenzenes as Ligands in Catalysts \\
\hline & Diazocines \\
\hline 5.1 & Synthesis \\
\hline & Cross-Coupling Reactions \\
\hline & Conclusion \\
\hline
\end{tabular}

Key words azobenzene, diazocine, molecular switches, cross-coupling reactions, $\mathrm{C}-\mathrm{H}$ activation, metal-catalyzed

\section{Introduction}

Azobenzene and its derivatives are among the most investigated molecular switches. ${ }^{1}$ They can interconvert photochemically and thermally between their metastable $(E)$ and $(Z \text { )-isomers (Figure } 1)^{2}$
Figure 1 Reversible isomerization of azobenzene ${ }^{2}$

Several physicochemical characteristics are affected by this photoisomerization, e.g. geometry and end-to end distance, ${ }^{3}$ electronic properties, ${ }^{4}$ and polarity. ${ }^{2}$ Whereas $(E)$ azobenzene is planar ${ }^{3 \mathrm{a}}$ and without a dipole moment, ${ }^{4}(Z)-$ azobenzene shows a non-planar geometry ${ }^{3 \mathrm{~b}}$ and a dipole moment of 3.0 D. ${ }^{4}$ Consequently, azobenzene derivatives have gained great interest, for example for applications in data storage materials, ${ }^{5}$ dynamic molecular devices, ${ }^{1}$ or in photonics. ${ }^{6}$

Thus, manifold synthetic procedures have been developed for the preparation of azobenzene derivatives, ${ }^{7}$ most with the formation of the diazenyl group as the key step. Methods to obtain symmetric azobenzenes range from reductive coupling of nitrobenzenes ${ }^{8}$ or oxidative coupling of anilines. ${ }^{9}$ The Mills reaction ${ }^{10}$ or azo-coupling reactions ${ }^{11}$ can be used to prepare asymmetric azobenzene derivatives. However, functionalized azobenzenes obtained in this way usually require prefunctionalized starting materials ${ }^{7}$ which limits the synthetic modification possibilities. An additional problem is the susceptibility of the diazenyl group towards oxidizing ${ }^{11 b, 12}$ and reducing ${ }^{13}$ agents. Therefore, latestage modification through cross-coupling reactions provides a valuable alternative to access a wider variety of azobenzene derivatives. This short review aims to give a broad, but not exhaustive, overview of the synthetic possibilities offered by cross-coupling reactions on azobenzenes and diazocines. In this short review, we distinguish between azobenzenes as formally electrophilic and formally nucleo- 


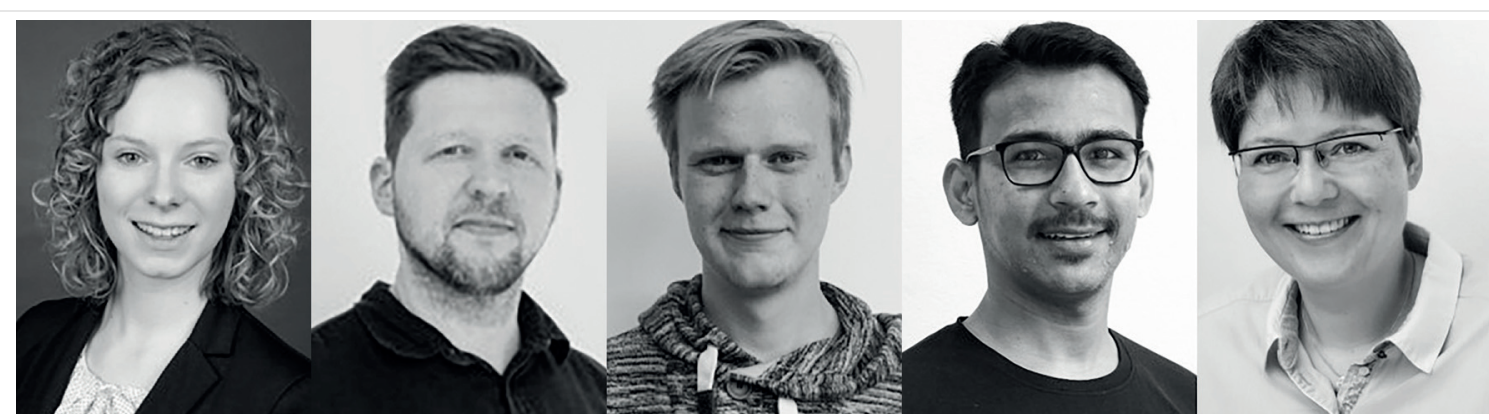

(from left to right) Melanie Walther studied chemistry and business administration at the University of Kiel. After research stays at Cardiff University as well as at Stockholm University, she joined the Staubitz group for her master's thesis, dealing with photoswitchable polysiloxanes. During her following doctoral study at the University of Bremen she wants to expand the synthetic scope of molecular switches and their application into materials. Waldemar Kipke studied biochemistry at Leibniz University in Hannover and obtained his bachelor's degree in 2016. He wrote his master's thesis about new ethylene-bridged molecular switches and obtained his master's degree in October 2018. During his Ph.D., he continues to work on molecular switches and new heterocycles containing B, Zr, and Sn.

Sven Schultzke studied chemistry at the University of Kiel and joined the Staubitz group for his bachelor's thesis about organogold(I) cross-coupling reactions. His upcoming research has been based on photoswitchable molecules, starting with a research exchange to the University of British Columbia in Vancouver for his master thesis and now his doctoral study, where he designs smart materials for 'soft grippers'.

Souvik Ghosh completed his M.Sc. from SVNIT, India. During his studies, he was a DAAD scholar at KIT, Germany and a OIST research scholar at OIST, Japan. In 2018, he joined the Staubitz group as Ph.D. student focusing on the synthesis of novel switchable molecules and their application in materials and polymer sciences.

Anne Staubitz was an assistant professor at the University of Kiel, before moving to the University of Bremen in 2015, where she has a full professorship for organic functional materials. Her main interests are light and force sensitive materials. The primary research focus is on their syntheses and properties, as well as applications. The second large research area in the group is comprised of compounds and materials that contain unusual combinations of main group elements and heavier elements.

philic components because of the different requirements and the corresponding difficulties in the synthesis of the azobenzene precursors, especially for nucleophilic derivatives.

\section{Azobenzenes as Formally Electrophilic Components}

(Pseudo)halogenated azobenzenes are used as an electrophilic component in cross-coupling reactions with a large variety of organometallic (nucleophilic) coupling partners. These (pseudo)halogenated species are usually obtained by employing prefunctionalized building blocks. ${ }^{7}$ There are very few reported examples of the direct halogenation of azobenzene derivatives. ${ }^{14}$ The relatively low reactivity of azobenzenes towards electrophilic halogenation reactions results from the electronic properties of the diazenyl group, which can form adducts with halogen halides leading to low yields. ${ }^{14, b}$ The use of elemental halogens often results in inseparable mixtures of mono-, di-, tri-, and tetrahalogenated products. ${ }^{14 a, c, d}$ Due to the lone-electron pairs on the nitrogen atoms, the diazenyl group can coordinate to metal catalysts facilitating substitution in the orthoposition. ${ }^{14 \mathrm{e}}$ ortho-Halogenation is thus possible via metalcatalyzed $\mathrm{C}-\mathrm{H}$ activation. ${ }^{14 c, e, f}$ However, different coordination patterns of the metal catalyst on the azobenzene moiety have been detected. ${ }^{14 \mathrm{~d}}$ Thus, selective halogenation remains challenging. ${ }^{14 \mathrm{e}}$

\subsection{Palladium Catalysis}

Palladium catalysts are the most frequently used catalysts in cross-coupling reactions. Therefore, the high number of palladium-catalyzed cross-coupling reactions of azobenzene derivatives that serve as a formally electrophilic component is no surprise.

\subsubsection{Suzuki-Miyaura Cross-Coupling Reactions}

The Suzuki-Miyaura cross-coupling reaction of (pseudo)halogenated azobenzenes with boronic acids or esters is one of the most frequently used cross-coupling reactions for the modification of azobenzenes. Due to its convenience, reliability, and high yields, it is often used as the final synthetic step to combine large building blocks. ${ }^{15}$ Of the many available examples, in this review we place a certain focus on polymers or molecules that self-assemble: such larger molecules are often not easy to prepare and this is where the benefits of the Suzuki-Miyaura cross-coupling are most relevant. Consequently, the Suzuki-Miyaura crosscoupling reaction gives access to many azobenzene derivatives with new applications in self-assembled materials ${ }^{15 a}$ or many liquid crystals, ${ }^{15 b-d, 16}$ compounds that show tunable fluorescence, ${ }^{17}$ photoswitchable porphyrin systems, ${ }^{15 e-g}$ dendrimers, ${ }^{15 \mathrm{~h}}$ polymers, ${ }^{15 i-0}$ metal-organic frameworks (MOFs), ${ }^{15 p}$ as well as molecular machines such as rotaxanes. ${ }^{15 q, \mathrm{r}}$ 
The first successful Suzuki-Miyaura cross-coupling reaction of an azobenzene derivative was described in a polymerization reaction (Scheme 1); ${ }^{15 i}$ different conjugated polymers were synthesized with molecular weights up to $M_{n}=9700$ (in yields of $80-99 \%$ ).

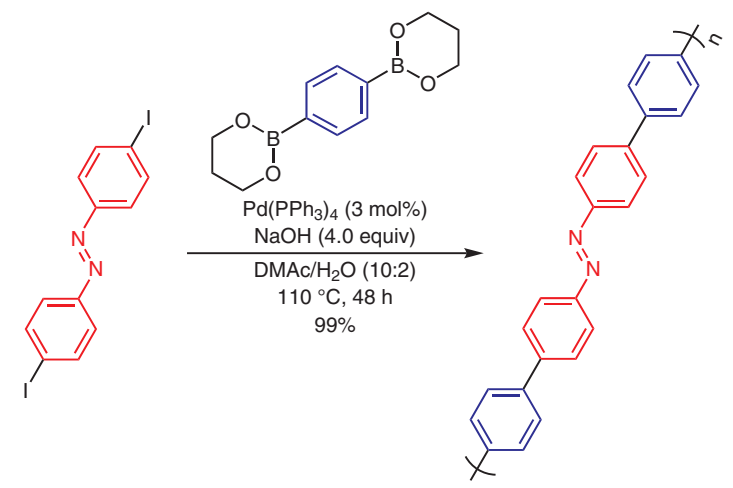

Scheme 1 Suzuki-Miyaura cross-coupling reaction for polymerization of an azobenzene derivative $\mathrm{e}^{15 i}$

Besides a benzene ring, ${ }^{15 i}$ more complex motifs such as a fluorene ring ${ }^{15 \mathrm{j}, 1, \mathrm{n}, \mathrm{o}}$ or a carbazole ring ${ }^{151, \mathrm{~m}, \mathrm{o}}$ were successfully integrated in the conjugated main chain.

For the synthesis of rotaxanes, azobenzene derivatives were connected with two $\alpha$-cyclodextrin units resulting in a [3]-rotaxane, ${ }^{18}$ and later on a [1]-rotaxane. ${ }^{15 q, \mathrm{r}}$ The azo- benzene motif was either trapped in or bonded directly to the $\alpha$-cyclodextrin units and subsequently capped by benzo[de]isoquinoline derivatives via cross-coupling. ${ }^{15 q, r, 18}$

Further possibilities are demonstrated by the implementation of two consecutive Suzuki cross-coupling reactions. Starting from a 4,4'-diiodoazobenzene, initial coupling with 4-bromophenylboronic acid gave a 4,4'-bis(4bromophenyl)azobenzene that underwent a second crosscoupling reaction with a 4-substituted phenylboronic acid to give an azoterphenyl derivative (37-54\% over 2 steps). ${ }^{19}$

Since 2016, several cross-coupling reactions have been performed using asymmetric azobenzene derivatives; in this way, molecules capable of precise self-assembly with additional non-covalent interactions were prepared in yields ranging from $26 \%$ to $94 \%$ (Scheme 2, A-C). ${ }^{15 c, 16,17}$ Suzuki-Miyaura cross-coupling was also applied to functionalize nickel porphyrin systems with azobenzene moieties in excellent overall yields (Scheme 2, D). ${ }^{15 \mathrm{f}} \mathrm{Pd}\left(\mathrm{PPh}_{3}\right)_{4}$ served as $\mathrm{Pd}(0)$ catalyst with $\mathrm{K}_{2} \mathrm{CO}_{3}$ as base and the reaction was carried out in a toluene/EtOH/water mixture at $90{ }^{\circ} \mathrm{C}$ leading to good and sometimes excellent yields. The coupling was even successful with an azopyridine and with adjusted conditions for an azoimidazole unit. For the latter, the free amine of the imidazole was $\mathrm{N}$-methylated to prevent a possible side reaction with $\mathrm{PdCl}_{2}$ (dppf) as the $\mathrm{Pd}(\mathrm{II})$ catalyst. $^{15 \mathrm{f}}$
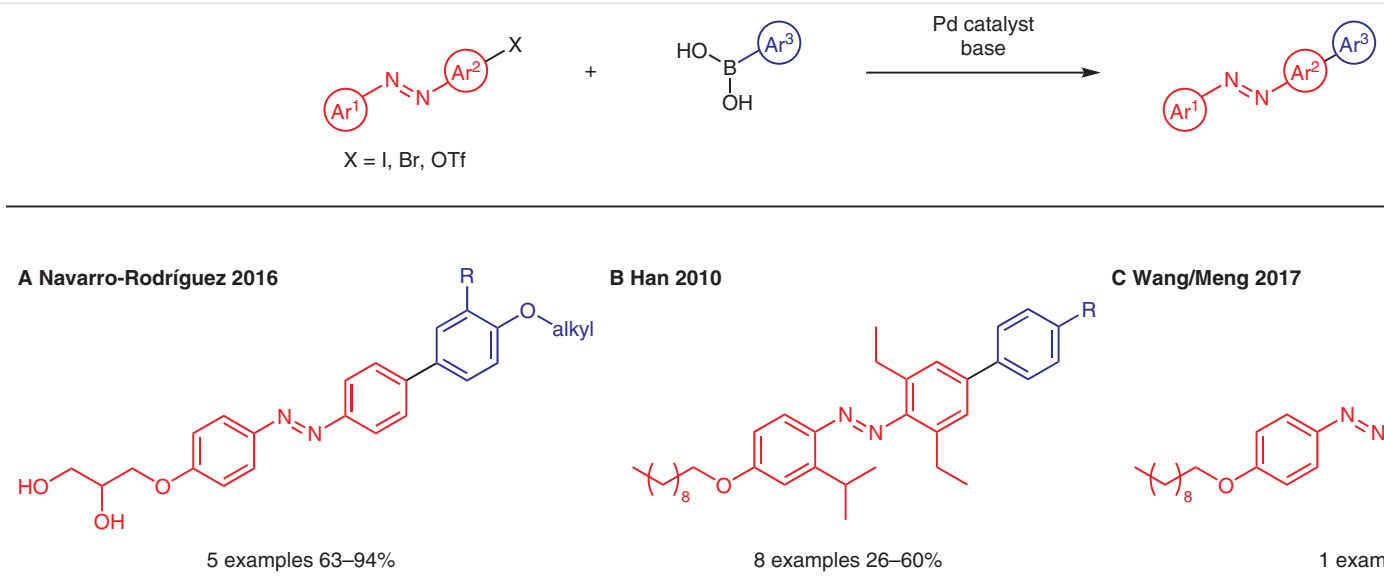<smiles>C[13CH](Oc1ccc(/N=N/c2ccc(-c3ccc4cc5ccccc5cc4c3)cc2)cc1)C(C)(C)C</smiles>

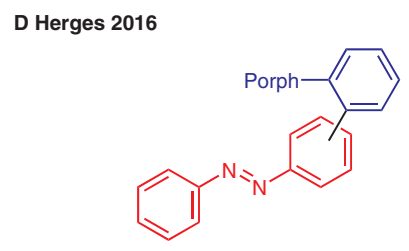

3 examples $93-97 \%$

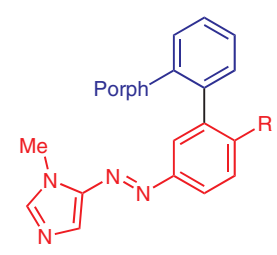

4 examples $66-93 \%$

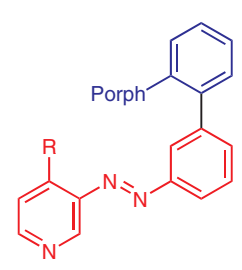

3 examples 90 to $>99 \%$

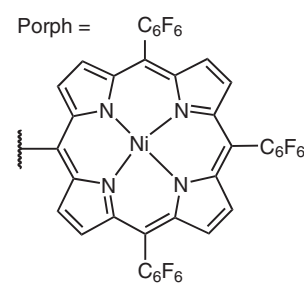

Scheme 2 Pd-catalyzed Suzuki-Miyaura cross-coupling reactions for enlarging a planar system $(A-C)^{15 c, 16,17}$ and for the functionalization of porphyrin systems (D) $)^{15 f}$ 


\subsubsection{Sonogashira Cross-Coupling Reactions}

The palladium-catalyzed cross-coupling reaction of a terminal alkyne with halogenated azobenzenes represents another widely used functionalization possibility. In this way, an azobenzene unit can be connected with relatively long, rigid, and $\pi$-conjugated linkers in good to excellent yields. ${ }^{20}$ The incorporated linkers then serve a specific function in the molecule: For example, the functionalization of ethynyl-1,6-methano[10]annulenes with azobenzene demonstrated the synthesis of electron-donor/acceptor systems that are suitable substrates for nonlinear optics or liquid crystals (Scheme 3, A). ${ }^{20 a}$ In different azobenzene systems for the synthesis of photochromic self-assembled monolayers, the rigid linker ensures sufficient control over the distance from the headgroup to the surface and features a cooperative switching behavior of the azobenzene units. ${ }^{20 b-d}$

Hydrophobic fluorescent azobenzenes were transformed into water-soluble fluorescent 2-borylazobenzenes by incorporating ionic functional groups via Sonogashira coupling. ${ }^{20 e}$ Employing 4,4'-diiodoazobenzene as the starting material enabled a double cross-coupling; in this way, an azobenzene moiety containing two paramagnetic nitroxide spin labels was synthesized in which the ethynyl groups supported the formation of spin exchange coupling (Scheme 3, B left). ${ }^{20 f}$ Low-molecular organogelators were obtained by double cross-coupling of 3,3'-diiodoazoben- zene with acetylene derivatives (Scheme 3, B right). ${ }^{20 g}$ The two urethane moieties were required for strong hydrogen bonding, whereas the two cholesterol units led to relatively weak van der Waals interactions. ${ }^{20 \mathrm{~g}}$ Moreover, an azobenzene bisporphyrin system ${ }^{20 d}$ as well as different para-alkynylazobenzene ligands and their corresponding organometallic cobalt complexes were obtained. ${ }^{20 \mathrm{~h}}$ As azotolanes usually show liquid crystallinity as well as highly birefringent features, this method was utilized for the synthesis of several azotolane monomers ${ }^{20 \mathrm{i}, j}$ or polymers with azobenzene in the side chain ${ }^{20 k}$ or main chain ${ }^{201-n}$ (Scheme 3, C), respectively. Additionally, photoresponsive and fluorescent co-polymers (Scheme 3, D), ${ }^{200}$ polyamide-phenyleneethynylenes ${ }^{20 \mathrm{p}}$ or a semiconducting colloidal porous organic polymer ${ }^{20 \mathrm{q}}$ were obtained. The scope of electrophilic azobenzene cross-coupling partners was successfully broadened to bistriflates for the synthesis of rigid dendrimers in an acceptable yield. ${ }^{20 s, t}$

2-Iodoazobenzene reacted with (trimethylsilyl)acetylene under Sonogashira conditions, but even after optimization of the reaction conditions the yield of 2-[(trimethylsilyl)ethynyl]azobenzene remained $50 \% .{ }^{21}$ Additionally, the product decomposed during workup because of the lability of the protecting group and the instability of the deprotected diazene. Coupling with more robust (triisopropylsilyl)and (triethylsilyl)acetylene solved both problems and the product 2-[(trialkylsilyl)ethynyl]azobenzenes were obtained in $97 \%$ and $87 \%$ yield, respectively. ${ }^{21}$

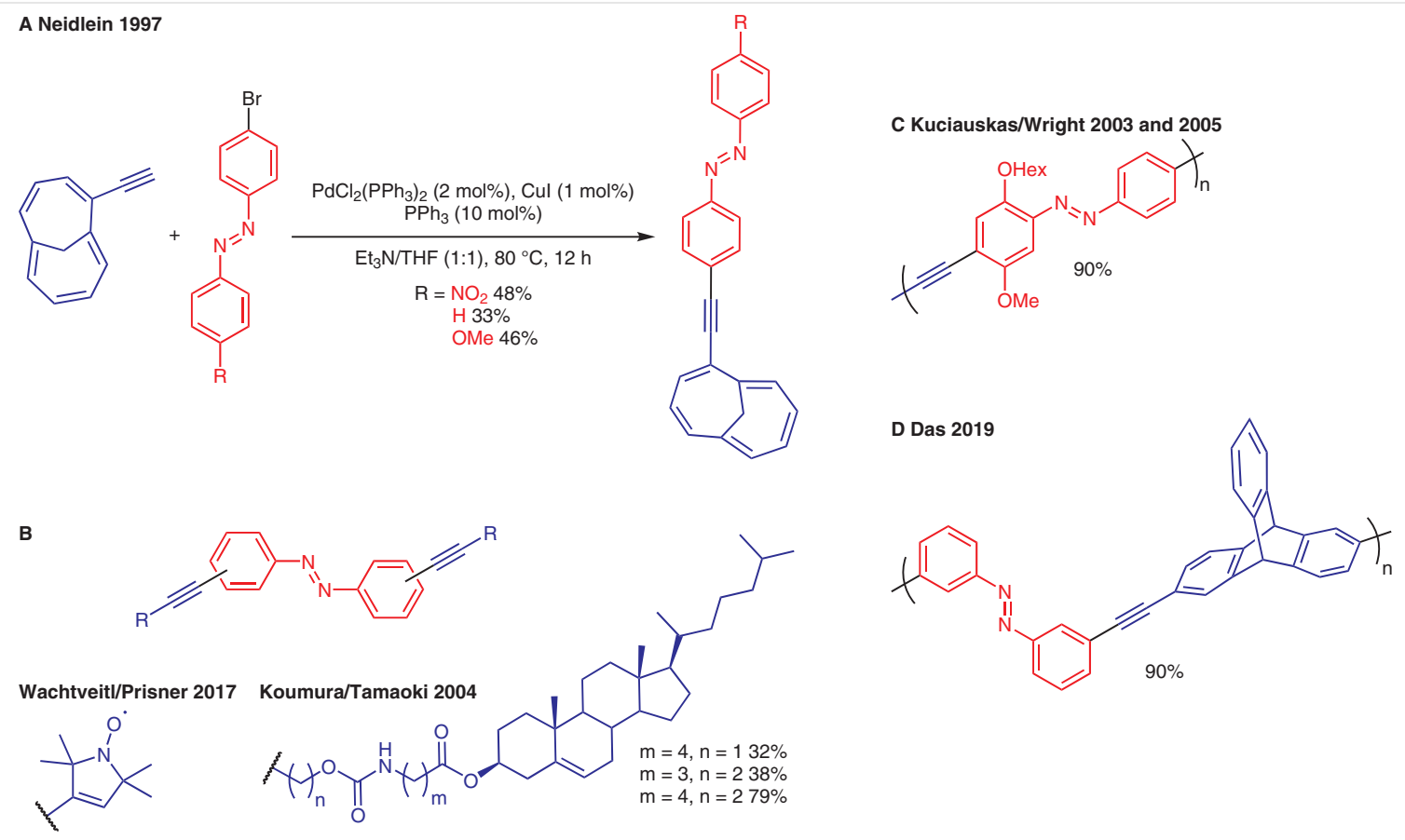

Scheme 3 Pd-catalyzed Sonogashira cross-coupling reactions of halogenated azobenzenes ${ }^{20 a, f, g, l, m, o}$ 


\subsubsection{Buchwald-Hartwig Cross-Coupling Reactions}

This type of cross-coupling reaction is used to form C-N bonds. In 2020, the coupling of 3,5-dibromoazobenzene with $N$-Boc- $N$-(4-methoxyphenyl)hydrazide to give 3,5bis[ $N^{\prime}$-Boc- $N^{\prime}$-(4-methoxyphenyl)hydrazino]azobenzene in $58 \%$ yield was reported (Scheme 4 ). ${ }^{22}$ The obtained product was then oxidized to yield a $C_{2}$-symmetric 3,5-bis(4-methoxyphenylazo)azobenzene. Unsymmetric tris(arylazo)benzenes were accessible by sequential coupling. ${ }^{22}$

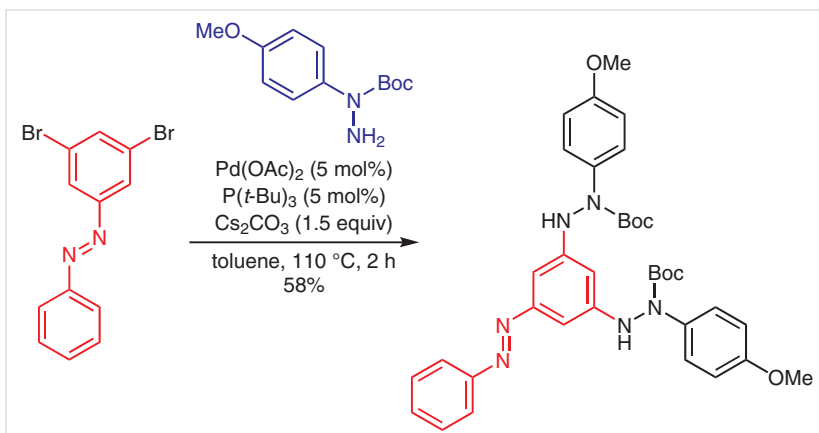

Scheme 4 Pd-catalyzed Buchwald-Hartwig cross-coupling reaction of 3,5-dibromoazobenzene ${ }^{22}$

\subsubsection{Heck Reactions}

The Heck reaction can be employed in order to preserve double bonds within the starting material for later functionalization. As with the Suzuki-Miyaura cross-coupling, we mainly discuss reports of larger functional polymers and assemblies. One interesting example is the functionalization of cage silsesquioxanes with azobenzene units via the Heck reaction (Scheme 5). ${ }^{23}$ The synthesis of new azobenzene-doped hybrid porous polymers was thus possible. ${ }^{24}$

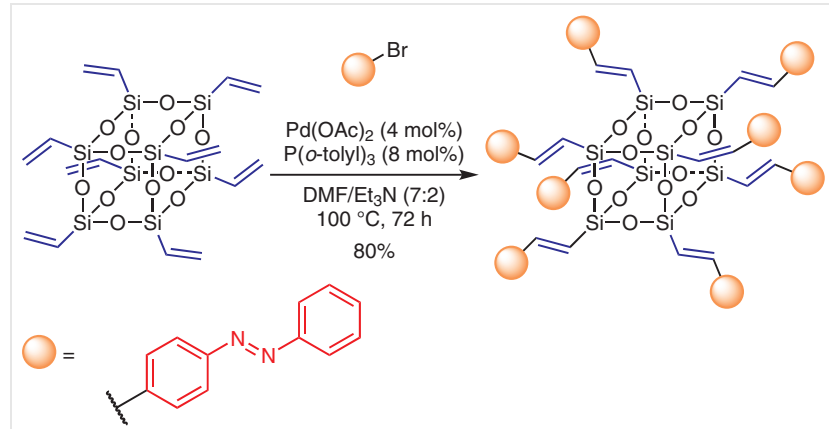

Scheme 5 Pd-catalyzed Heck reaction of 4-bromoazobenzene ${ }^{23}$

Poly(phenylenevinylene)-based conjugated polymers with azobenzene derivatives incorporated directly in the $\pi$ conjugative building units were prepared in quantitative yield and with a high molecular weight $\left(M_{n}>10000\right)$ by coupling polymerization of divinylbenzenes with 4,4 '-di- haloazobenzenes. ${ }^{25}$ The Heck reaction of nipecotic acid (piperidine-3-carboxylic acid) derivatives with azobenzene triflates and iodides yielded vinyl ethers in good yields. However, the coupling was not possible for ortho-substituted azobenzenes. In this case, the Heck reaction needed to be performed with 1-iodo-2-nitrobenzene with the formation of the azobenzene by an azo coupling in a later step. ${ }^{26}$

\subsubsection{Stille Reactions}

In a Stille cross-coupling reaction, an organotin compound is reacted with a halide. Organostannanes are easy accessible and stable in air and moisture so that a broad range of functional groups can be used under mild conditions. ${ }^{201,25,27}$ In this way, 4,4'-dibromoazobenzene was coupled with tributylvinyltin to yield 4,4'-divinylazobenzene in $70 \%$ yield. ${ }^{25}$ It was also possible to introduce heteroaromatic compounds into a polymer backbone via a Stille cross-coupling: The monomer 4,4'-diiodoazobenzene was reacted with four different bis(trimethylstannyl)-substituted heteroaromatic compounds to give poly(phenylene)basedpolymers that were soluble in common organic solvents in moderate to excellent yields (Scheme 6). ${ }^{27}$ Due to the extended main-chain conjugation, the thiophene-, furan-, and $\mathrm{N}$-methylpyrrole-containing poly(phenylenes) showed strongly red-shifted absorptions in the visible region. Only the pyridine-containing poly(phenylene) had a low degree of main-chain conjugation, but contrary to other examples, it showed in solution reversible photoisomerization of azobenzene units with an accompanied change of the electrochemical properties. The $(Z)$-enhanced polymer was less susceptible to oxidation. ${ }^{27}$

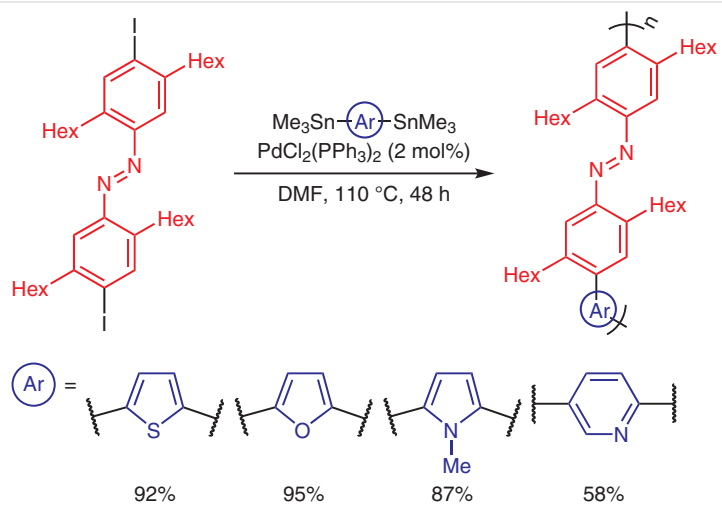

Scheme 6 Pd-catalyzed Stille cross-coupling reactions of diiodoazobenzenes ${ }^{27}$

\subsection{Nickel Catalysis}

Although palladium complexes are the most common catalysts in cross-coupling reactions, attempts have been made to replace palladium by less expensive metals such as nickel. For example, a nickel-catalyzed Heck reaction of aryl 
triflates with vinyl ethers proceeded under mild reaction conditions, using a catalytic system consisting of bis(cyclooctadiene)nickel(0), 1,1'-bis(diphenylphosphino)ferrocene (DPPF), and tertiary amine $\mathrm{Cy}_{2} \mathrm{NMe}$, followed by hydrolysis to give the corresponding acetyl-substituted products with good functional group tolerance. It was also possible to incorporate a photoswitchable unit by the olefination of an azobenzene triflate followed by hydrolysis to give the corresponding acetyl derivative (Scheme 7). ${ }^{28}$

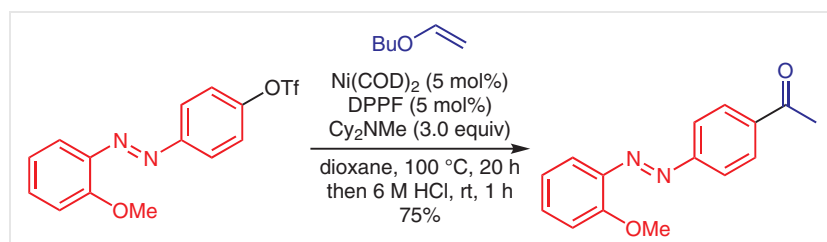

Scheme 7 Ni-catalyzed Heck reaction of an azobenzene triflate derivative $^{28}$

\subsection{Copper Catalysis}

Copper catalysts are another alternative to palladium catalysts in cross-coupling reactions to obtain substrates otherwise not accessible.

\subsubsection{Cadiot-Chodkiewicz Reactions}

The copper-catalyzed Cadiot-Chodkiewicz reaction enables the formation of conjugated dienes. A synthetic route towards large-scale highly ordered porous structures from organometallic precursors via spontaneous self-assembly was established by using a two-step Cadiot-Chodkiewicz cross-coupling. Several neutral platinum-acetylide complexes with azobenzene groups in the center and long alkyl chains on both ends of the molecule were obtained in excellent to quantitative yields (Scheme 8). ${ }^{29}$ In a similar fashion, poly(platinaynes) were synthesized with both meta- or para-substituted azobenzene spacers to compare their optoelectronic properties. In these complexes, the acetylidefunctionalized azobenzene ligands could still undergo photoisomerization reversibly, although the switching process appeared to be more facile for para-substituted systems and with lower photoisomerization in solution in comparison to smaller systems. ${ }^{30}$

\subsubsection{Ullmann Reactions}

The Ullmann reaction is a powerful tool for $\mathrm{C}-\mathrm{N}$ bond formation. The Ullmann coupling of 4,4'-dibromoazobenzene with 3,6-bis(9H-carbazol-9-yl)-9H-carbazole gave a bis(tercarbazole)azobenzene derivative in $46 \%$ yield that was used as a precursor for the fabrication of photoresponsive microporous films (Scheme 9). ${ }^{31}$

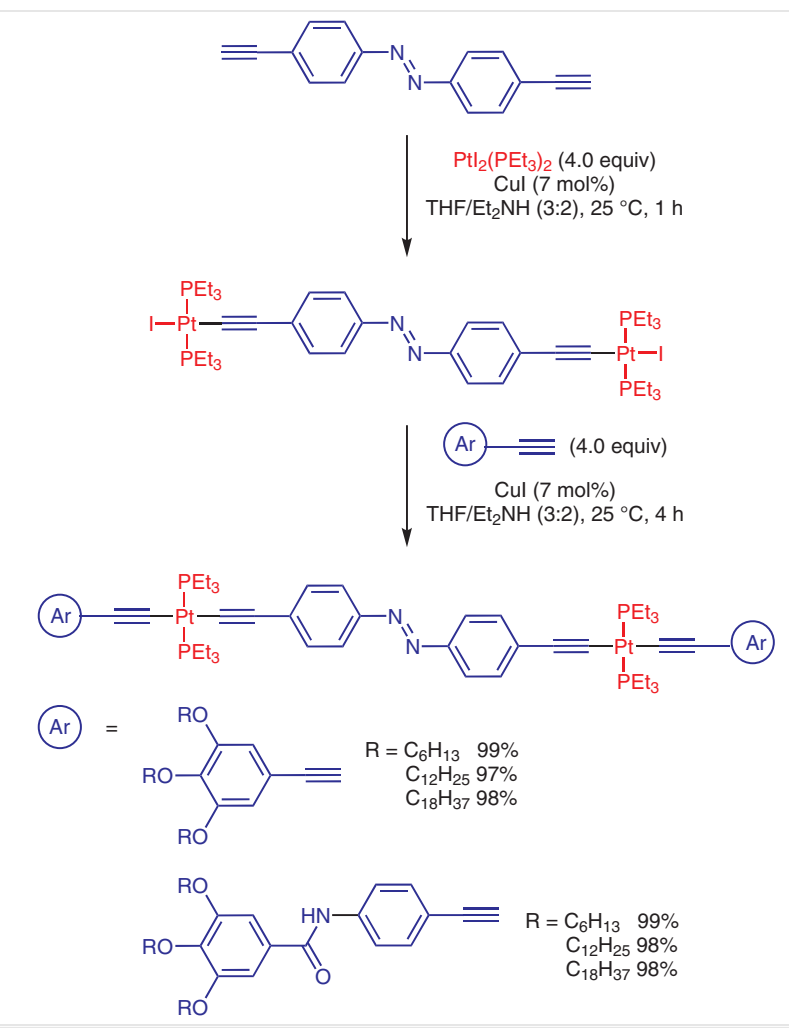

Scheme 8 Cu-catalyzed two-step Cadiot-Chodkiewicz cross-coupling reaction of alkynyl-functionalized azobenzenes ${ }^{29}$
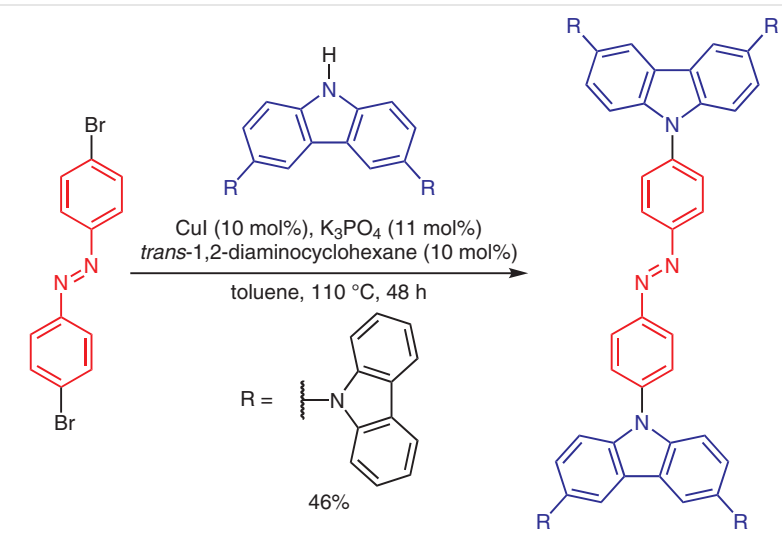

Scheme 9 Cu-catalyzed Ullmann coupling of dibrominated azobenzene $^{31}$

\subsection{Cobalt Catalysis}

Another alternative to palladium catalysis is the use of cobalt as an inexpensive metal. For example, the $\mathrm{C}\left(\mathrm{sp}^{2}\right)-\mathrm{P}$ cross-coupling of vinyl, styryl, and aryl halides with diphenyl phosphine oxide and dialkyl phosphinate using a unique $\mathrm{Co} / \mathrm{Cu}$ catalytic system gave the corresponding 
phosphoryl-substituted products. This protocol showed robust functional group tolerance that enabled the coupling of 4,4'-diiodoazobenzene with diisopropyl phosphite to give $4,4^{\prime}$-bis(diisopropoxyphosphoryl)azobenzene in $76 \%$ yield (Scheme 10). ${ }^{32}$
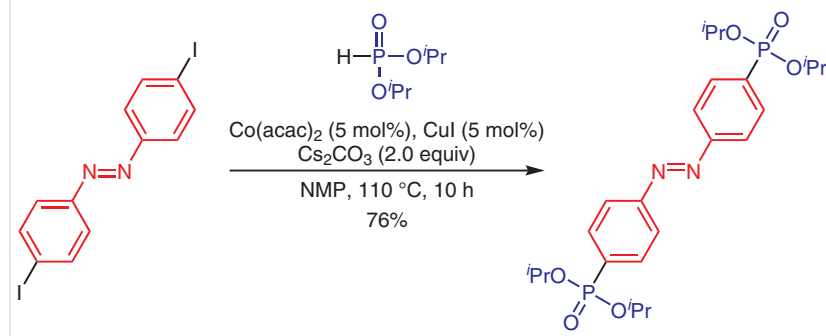

Scheme $10 \mathrm{Co} / \mathrm{Cu}$-catalyzed $\mathrm{C}\left(\mathrm{sp}^{2}\right)-\mathrm{P}$ cross-coupling reaction of 4,4'-diiodoazobenzene ${ }^{32}$

\section{Azobenzenes as Formally Nucleophilic Components}

In cross-coupling reactions, the formal nucleophile is an (organo)metallic species. Organometallic, nucleophilic azobenzene derivatives can be obtained either by halogenmetal exchange of the (pseudo)halogenated azobenzene or by applying an appropriate cross-coupling reaction with a dimetallic reagent (Scheme 11, A) (see later for $\mathrm{C}-\mathrm{H}$ activation). ${ }^{7 \mathrm{~b}, 33}$ However, in the case of azobenzenes, halogenmetal exchange can lead to the reduction of the azo group as a dominating side reaction (Scheme 11, B). ${ }^{34}$ From the perspective of the formally nucleophilic azobenzene, the main limitation is access to the azobenzene starting material. There has been very little research performed in this area in terms of systematic investigations and thus, it is difficult to distill common principles or indeed select the most seminal papers.

\subsection{Palladium Catalysis}

Palladium catalysts are also most commonly used in cross-coupling reactions involving azobenzene derivatives as the formally nucleophilic component. In terms of the obtained product structure, the same criteria apply for the selection of the specific cross-coupling reaction as are utilized for electrophilic azobenzene derivatives. However, a key consideration is the availability of the metalated azobenzene.

\subsubsection{Suzuki-Miyaura Cross-Coupling Reactions}

The first use of an azobenzene derivative as a nucleophile in a Suzuki-Miyaura cross-coupling reaction was reported in $2007 ;^{36}$ the coupling of a boronic acid pinacol ester functionalized azobenzene with diverse iodoarenes gave arylate azobenzenes in $41-72 \%$ yields. ${ }^{36}$ While the cross-coupling reactions themselves are relatively unremarkable, the importance is in the synthesis of the starting material by cross-coupling of a (pseudo)halogenated azobenzene with the boronic ester. ${ }^{36,37}$ A second approach is the condensation of a nitrosobenzene and aniline boronic acid ester; the boronic acid ester is unaffected by the condensation reaction. ${ }^{36}$ Due to the efficiency of this method, a number of synthetic targets ${ }^{38}$ were assessed. Moreover, an azobenzene-4-boronic acid pinacol ester derivative was used as the nucleophile and 4-bromo-2,2,2',2'-tetrafluoroazobenzene derivatives as the electrophile, which enabled the use of azobenzene as both cross-coupling components. The resulting product undergoes orthogonal switching, where the azobenzene units are switched separately to give 4 different isomers by green, blue, or ultraviolet light or electrocatalytic isomerization (Scheme 12). ${ }^{37}$
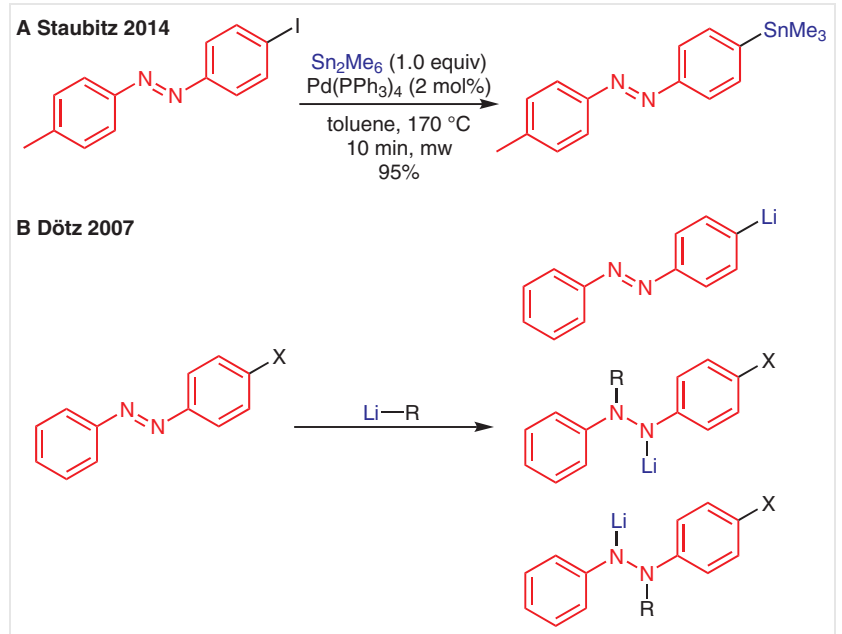

Scheme 11 (A) Stille-Kelly cross-coupling reaction of 4-iodo-4'-methylazobenzene with hexamethyldistannane; ${ }^{33}$ (B) halogen-metal exchange of a halogenated azobenzene with the possible reduction of the diazenyl group ${ }^{35}$

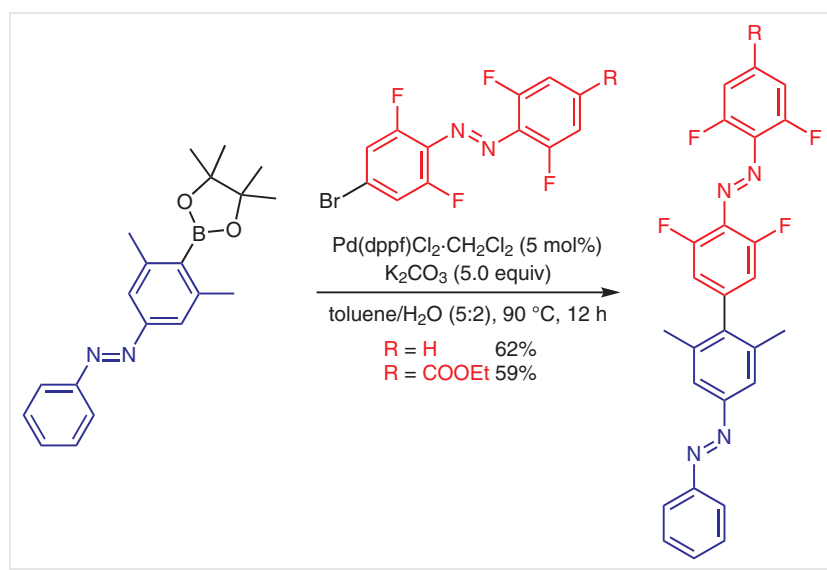

Scheme 12 Pd-catalyzed Suzuki-Miyaura cross-coupling reaction of an azobenzene-4-boronic acid pinacol ester and 4-bromo-2,2,2', $2^{\prime}$ tetrafluoroazobenzene derivatives ${ }^{37}$ 


\subsubsection{Sonogashira Cross-Coupling Reactions}

In 2014, the preparation of an azobenzene liquid crystal was reported by the Sonogashira cross-coupling reaction of an ethynyl-substituted azobenzene with 1-bromooctane. ${ }^{39}$ This protocol was utilized in 2017 for the coupling of an azobenzene derivative with aryl bromides (Scheme 13, A). ${ }^{15 d}$ The Sonogashira cross-coupling reaction has also been used for the synthesis of artificial helical oligomers ${ }^{40}$ or polymers ${ }^{41}$ in which the photoisomerization of the azobenzene moieties triggers a geometric change. Novel azobenzene-containing hydroxyphenylglycine-derived poly( $m$-phenyleneethynylene)s were synthesized by polymerization through the Sonogashira couplings (thus formally a polycondensation) of 3,5-diethynylazobenzenes with various diiodinated amides (Scheme 13, B). ${ }^{41 \mathrm{a}}$

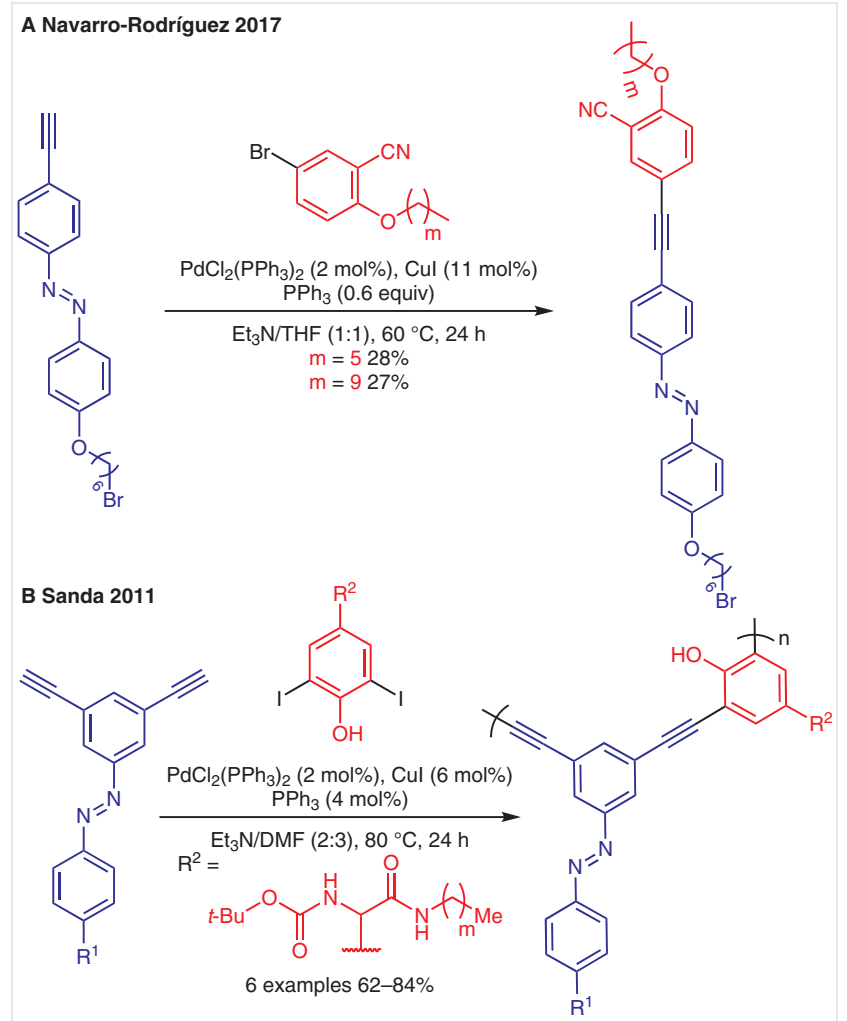

Scheme 13 Pd-catalyzed Sonogashira cross-coupling reactions of alkynyl-functionalized azobenzenes ${ }^{15 d, 41 a}$

Furthermore, the Sonogashira reaction was used to prepare a hairy-rod like $\pi$-conjugated polymer with a fluorene unit in the backbone. ${ }^{42}$ The late-stage functionalization of poly(aryl ethers) with azobenzene moieties was feasible, in which polymer bromo side groups react with 4-(dimethylamino)-3'-ethynylazobenzene. ${ }^{43}$

\subsubsection{Buchwald-Hartwig Cross-Coupling Reactions}

The Buchwald-Hartwig cross-coupling reaction can be used to form $\mathrm{C}-\mathrm{N}$ bonds. The Buchwald-Hartwig amination of various polystyrene and poly(iminoarylene) derivatives was reported to give the corresponding products with aminoazobenzene groups in the side chain (Scheme 14). ${ }^{44}$ The absence of characteristic stretching vibrations of the starting materials in the IR spectrum indicated a full loading of the obtained polymer. ${ }^{44}$

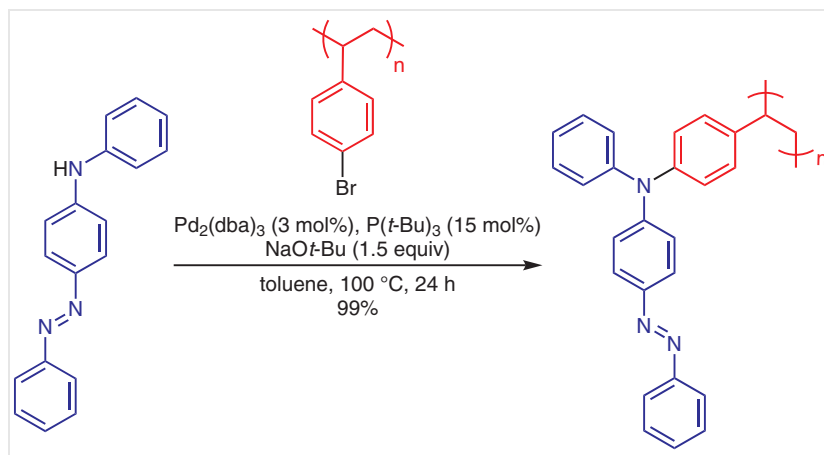

Scheme 14 Pd-catalyzed Buchwald-Hartwig amination of 4-(phenylamino)azobenzene ${ }^{44}$

This methodology was applied to the synthesis of amorphous materials such as branched triarylamine derivatives, ${ }^{45}$ a spiro-linked bifluorene ${ }^{46}$ as well as a perfluorocyclobutane (PFCB) aryl ether polymer ${ }^{47}$ or a poly(arylimino) derivative. ${ }^{48}$ It was even possible to prepare ferrocenophanes with azobenzene derivatives in the ligand and to use them as a redox-active and chromophore site showing potential as electron- or acid-responsive organic materials. ${ }^{49}$

\subsubsection{Heck Reactions}

The Heck reaction of dihaloazobenzenes with divinylarenes as well as the reverse case, the coupling of 4,4'-divinylazobenzene with dihaloarenes, to produce photoresponsive poly(phenylenevinylene)s was investigated. However, the obtained polymers were largely insoluble in common organic solvents, hence this route was discarded. ${ }^{25}$

\subsubsection{Stille Reactions}

An efficient microwave-assisted method to prepare stannylated azobenzenes was developed to circumvent the possible reduction of the diazenyl group during halogenmetal exchange. These organostannyl-substituted azobenzenes subsequently served as nucleophiles in high-yielding Stille cross-coupling reactions (Scheme 15). ${ }^{33}$ 

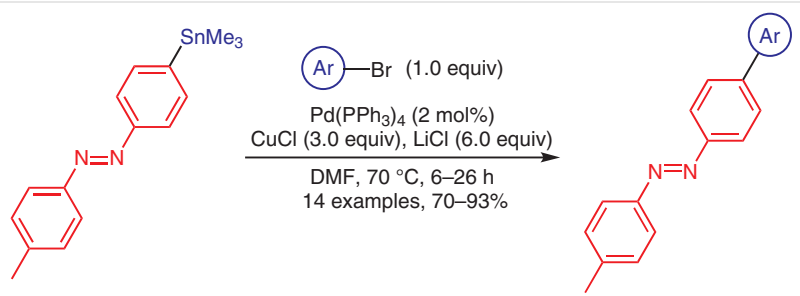

Scheme 15 Pd-catalyzed Stille cross-coupling reaction using stannylated azobenzene as nucleophile ${ }^{33}$

\subsection{Copper Catalysis}

A copper-catalyzed Ullmann cross-coupling reaction was the method of choice for the synthesis of bis[4(phenyldiazenyl)phenyl]amine and tris[4-(phenyldiazenyl)phenyl]amine by varying the stoichiometric quantities of the electrophilic component (Scheme 16)..$^{50}$
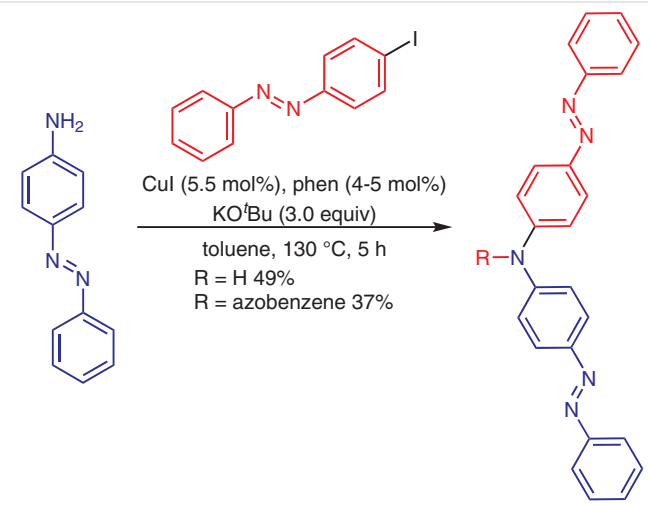

Scheme 16 Cu-catalyzed Ullmann cross-coupling reaction of 4-iodoazobenzene with amino-azobenzene ${ }^{50}$

The Ullmann cross-coupling reaction is also useful for generating phenol ethers through $\mathrm{C}-\mathrm{O}$ bond formation. In this way, a series of azobenzene-functionalized poly(ether sulfone)s were prepared, using a catalyst system of $\mathrm{CuI}$ and 2,2,6,6-tetramethylheptane-3,5-dione (TMHD), that had high glass transition temperatures $\left(T_{\mathrm{g}}>199{ }^{\circ} \mathrm{C}\right.$ ) (Scheme 17). ${ }^{51}$ Irradiation and writing/erasing experiments indicated a large photoinduced birefringence and good stability of the photoinduced orientation of the polymers. This makes them interesting for applications in reversible optical storage. ${ }^{51}$

This synthetic procedure was expanded to the synthesis of an azobenzene-containing poly(aryl ether) with carboxyl side groups capable of coordination to rare earth complexes. $^{43}$

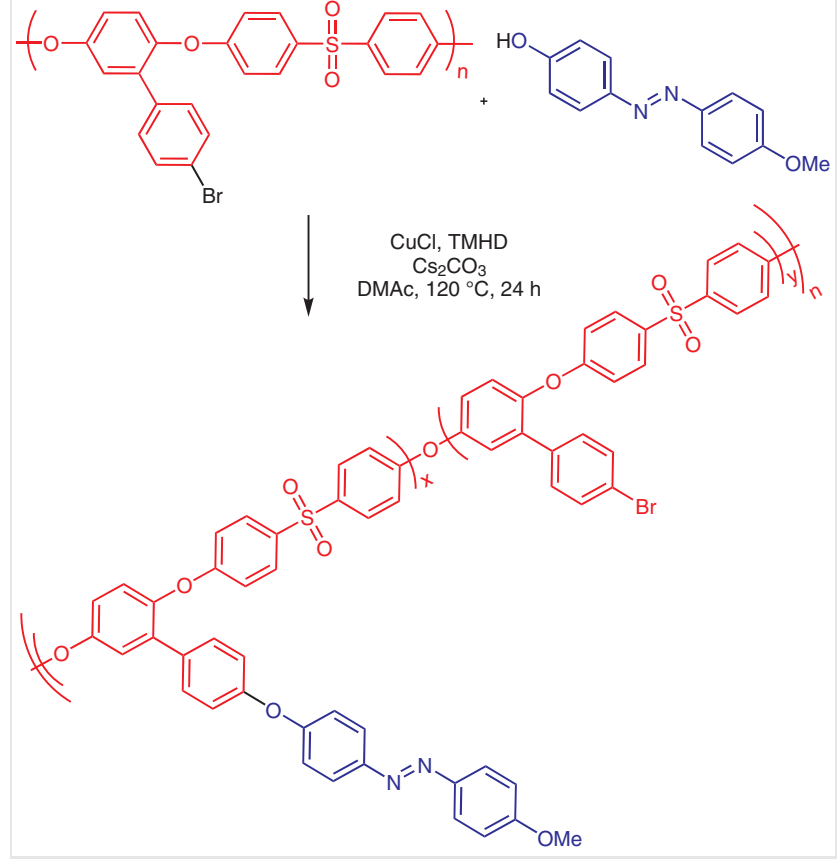

Scheme 17 Cu-catalyzed Ullmann cross-coupling reaction of poly(ether sulfone)s with bromine side groups and 4-[(4-methoxyphenyl)diazenyl]phenol with different functionalization degrees $(x=20,45,100)^{5}$

\subsection{C-H Activation Reactions}

C-H Activation reactions catalyzed by different transition metals have played an important role especially in the functionalization of azobenzene derivatives in the orthoposition.

\subsubsection{Palladium-Catalyzed C-H Activation Reactions}

The ortho-directing property of the azo group has been exploited in palladium-catalyzed $\mathrm{C}-\mathrm{H}$ activation reactions. ${ }^{14 e, 52}$ In many such reactions, the azobenzene is transformed by reaction with the diazenyl group. For example, azobenzenes were used for the synthesis of indazole backbones through palladium-catalyzed $\mathrm{C}-\mathrm{H}$ functionalization and subsequent intramolecular cyclization. ${ }^{52 a}$ In a similar approach, $3 \mathrm{H}$-indazol-3-ones were prepared from azobenzene derivatives using formic acid as carbon monoxide source (Scheme 18, A). ${ }^{52 \mathrm{~g}}$ ortho-C-H Amination of azoarenes with trimethylsilyl azide yielded 2-aryl-2H-benzotriazoles (Scheme 18, B). ${ }^{52 \mathrm{~b}}$ In this reaction, electrondonating substituents (alkyl, alkoxy) give higher product yields (58-87\%) than electron-withdrawing groups, such as $\mathrm{CF}_{3}(8 \%)$.

Late-stage functionalization of azobenzenes in the ortho-position was reported by the Trauner group (Scheme $19, \mathrm{~A}){ }^{14 \mathrm{e}}$ These tetra-ortho-chlorinated azobenzenes are of 
<smiles>CCOCCNc1ccccc1</smiles><smiles>CCO</smiles>

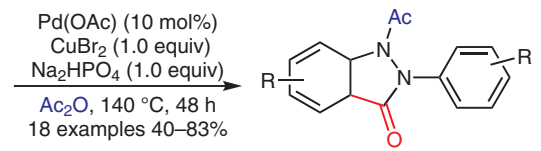

$\mathrm{R}=$ alkyl, ester, halogen

B Patel 2015

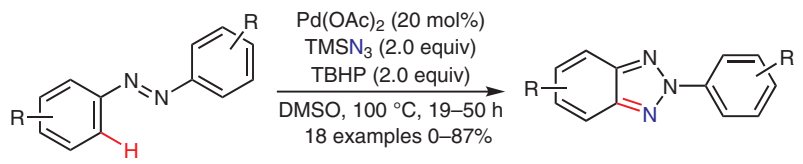

$\mathrm{R}=$ alkyl, alkoxy, halogen

Scheme 18 Pd-catalyzed C-H activation reactions of azobenzene derivatives yielding heteroaromatic compound $5^{52 \mathrm{~b}, \mathrm{~g}}$

special interest because of their redshifted isomerization to cis at $\lambda \approx 560 \mathrm{~nm}$. Azoarenes were functionalized with phenylhydrazine using a $\mathrm{Pd}(\mathrm{II})$ catalyst with atmospheric oxygen as the oxidant (Scheme 19, B). ${ }^{52 \mathrm{c}} \mathrm{Wu}$, Wang, and coworkers reported the acylation of azobenzene derivatives with benzylic ethers (Scheme 19, C). ${ }^{52 \mathrm{~d}}$

A Trauner 2016

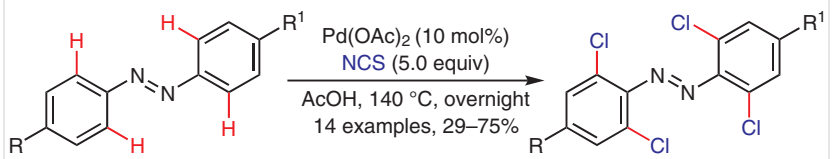

B Ye 2015

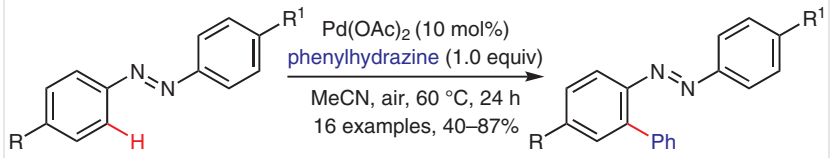

C Wu/Wang 2016<smiles>CC(=O)c1ccccc1N=Nc1ccccc1</smiles>

Scheme 19 Pd-catalyzed C-H activation reactions of azobenzene derivatives ${ }^{14 e, 52 c, d}$

\subsubsection{Rhodium-Catalyzed C-H Activation Reactions}

Rhodium has been shown to be a potent ortho $\mathrm{C}-\mathrm{H}$ activator of azobenzene derivatives. There are several reported examples of the formation of $\mathrm{C}-\mathrm{N}$ bonds, ${ }^{53} 2$-aryl-2H-ben- zotriazoles, ${ }^{54}$ and indazoles and indoles ${ }^{55}$ similar in yields to the palladium-catalyzed reactions. A very useful reaction is the ortho-heteroarylation of azobenzenes by rhodiumcatalyzed cross-dehydrogenative coupling (Scheme 20). ${ }^{56}$ Such conjugated biaryls might be of special interest for luminous materials.

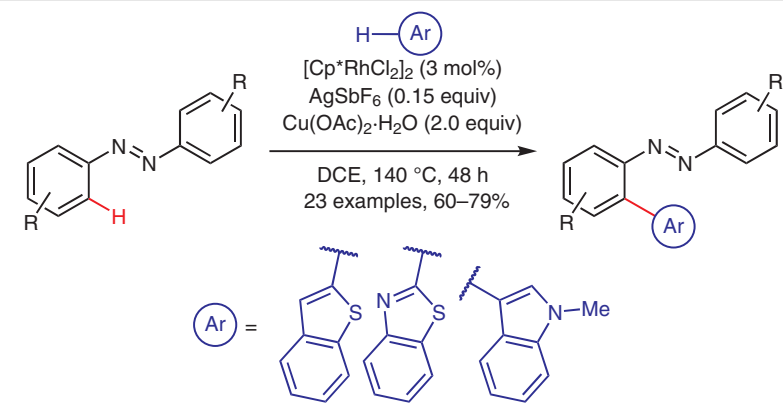

Scheme 20 Rh-catalyzed C-H activation reactions of azobenzene derivatives $^{56}$

\subsubsection{Ruthenium-Catalyzed C-H Activation Reactions}

Ruthenium-catalyzed $\mathrm{C}-\mathrm{H}$ activation reactions of azobenzene derivatives have been reported. ${ }^{57}$ Of particular interest is the meta/ortho-selective $\mathrm{C}-\mathrm{H}$ alkylation of azoarenes. Using a carboxylic acid promoted $\mathrm{Ru}(\mathrm{II})$-catalyzed $\mathrm{C}_{\mathrm{Ar}}-\mathrm{H}$ alkylation reaction of 4,4'-substituted azobenzenes with secondary and tertiary alkyl bromides gave selectively the meta-product (Scheme 21), ${ }^{58}$ while under the same reaction conditions, primary alkyl groups gave the ortho-product. To our knowledge this is the only reported reaction so far which allows $\mathrm{C}-\mathrm{H}$ activation in the meta position. Coupling with alkyl chlorides was unsuccessful. Furthermore, bulky groups, such as tert-butyl $(\mathrm{Y}=t$ - $\mathrm{Bu})$, on the azobenzene, prevented the reaction. ${ }^{58}$

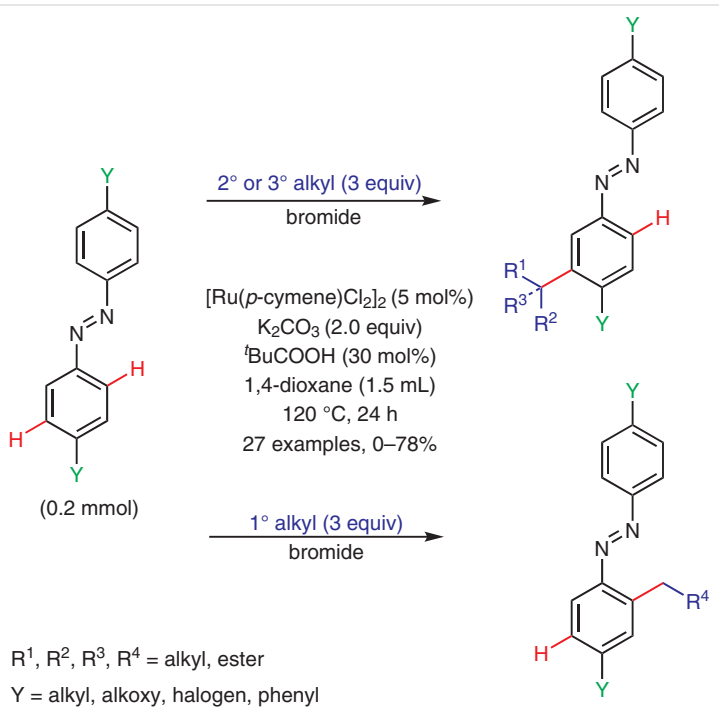

Scheme 21 Ru-catalyzed C-H activation reactions of azobenzenes ${ }^{58}$ 


\subsubsection{Cobalt-Catalyzed C-H Activation Reactions}

Cobalt-catalyzed $\mathrm{C}-\mathrm{H}$ activation reactions are largely unknown on azobenzene derivatives and only a few examples exist. ${ }^{59} \mathrm{~A}$ synthetic procedure for the azo-directed selective 1,4-addition of maleimides by $\mathrm{Co}(\mathrm{III})$-catalyzed $\mathrm{C}-\mathrm{H}$ activation was reported (Scheme 22). ${ }^{59 c}$ Worth noting is the use of low amounts of additives, as well as the fact that it does not require the use of a copper source. ${ }^{59 \mathrm{c}}$<smiles>[R]N1C(=O)C=CC1=O</smiles><smiles>[R]1cccc(/N=N/c2ccccc2)c1</smiles>

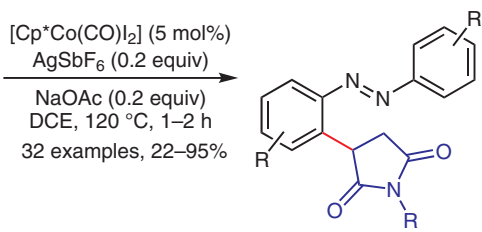

Scheme 22 Co-catalyzed C-H activation reactions of azobenzene derivatives $^{59 c}$

\subsubsection{Iridium-Catalyzed C-H Activation Reactions}

The Ir(III)-catalyzed [4+2] cyclization of azobenzenes with diazotized Meldrum's acid via a two-step reaction with an initial $\mathrm{C}-\mathrm{H}$ alkylation, followed by intramolecular annulation gave 3-oxo-2,3-dihydrocinnoline-4-carboxylic acids or esters depending on the solvent used (Scheme 23). ${ }^{60}$

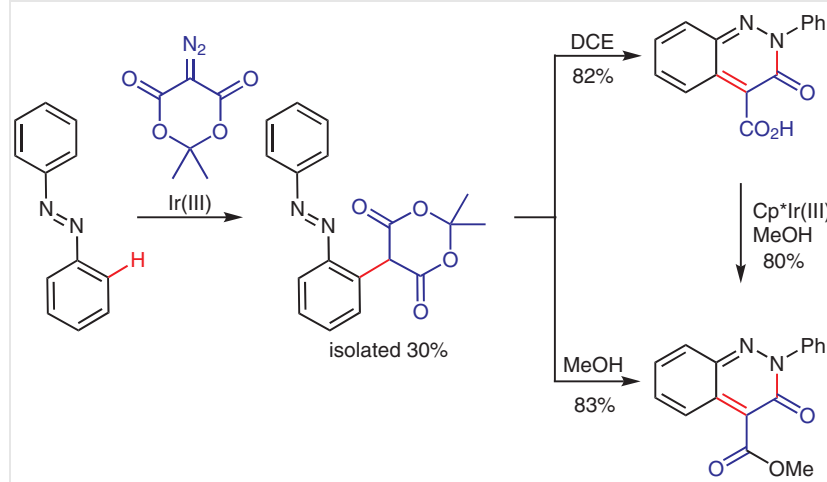

Scheme 23 Ir-catalyzed C-H activation reaction of azobenzene ${ }^{60}$

\subsubsection{Copper-Catalyzed C-H Activation Reactions}

Azobenzenes can be functionalized by a $\mathrm{Cu}(\mathrm{II})$-catalyzed aerobic oxidative amidation with amides yielding the corresponding 2-(acylamino)azobenzenes in moderate to excellent yields (Scheme 24). ${ }^{61}$<smiles>[R]c1ccc(/N=N/c2cccc([R])c2)cc1</smiles>

$\mathrm{R}^{1}, \mathrm{R}^{2}=$ alkyl, alkoxy, halogen $\mathrm{R}^{3}=$ alkyl, $\mathrm{H}, \mathrm{Ph}, \mathrm{PhCF}_{3}$ $\mathrm{R}^{4}=$ alkyl, $\mathrm{Ph}, \mathrm{CF}_{3}$

Scheme 24 Cu-catalyzed C-H activation reactions of azobenzene derivatives $^{61}$

\subsubsection{Iron-Catalyzed C-H Activation Reactions}

To date only one example of an iron-catalyzed $\mathrm{C}-\mathrm{H}$ activation reaction has been reported. An iron hydride complex bearing a 2,5-bis(di-tert-butylphosphinomethyl)pyrrolide ligand reacted with azobenzene. However, further functionalization was unsuccessful since the pentacoordinated aryl-iron complex was inert toward various reagents (Scheme 25). ${ }^{62}$
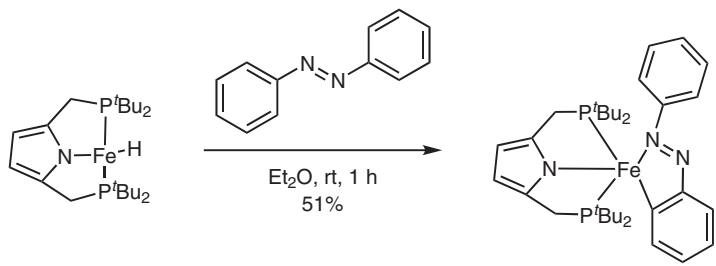

Scheme 25 Fe-catalyzed C-H activation of azobenzene ${ }^{62}$

\section{Azobenzenes as Ligands in Catalysts}

In addition to their use as a reactant in cross-coupling reactions, azobenzene derivatives can be also employed as ligands for catalysts in cross-coupling reactions. ${ }^{63}$ Here, the $\mathrm{N}$-donor capability of the diazenyl group (due to the lone electron pair on the nitrogen atoms) is used to form transition metal complexes. The incorporation of azo chromophores has enabled the synthesis of complexes with interesting physicochemical properties such as photoluminescence. Complexes with multidentate azoaromatic ligands are significantly stabilized because of the enhanced $\pi$-acceptor behavior compared to monocyclopalladated azobenzenes. $^{63 e}$ Although the synthesis of azo-containing phosphine $\mathrm{Pd}(\mathrm{II})$ and $\mathrm{Pt}(\mathrm{II})$ complexes was reported in 1999, and the first results of their catalytic use were demonstrated in Heck reactions, ${ }^{64}$ it took a further decade before this possibility was explored in more detail. ${ }^{63}$

In 2010, the synthesis of a polystyrene-anchored $\mathrm{Pd}(\mathrm{II})$ azo complex (Figure 2, A) and its application in the SuzukiMiyaura as well as Sonogashira cross-coupling reactions was reported; various aryl halides were reacted with phen- 
ylboronic acids or terminal alkynes in excellent yields (68$100 \%$ yield, 27 examples) under phosphine-free and aerobic reaction conditions in aqueous medium. ${ }^{63 \mathrm{~b}} \mathrm{~A}$ similar catalytic system showed comparable recyclability, but, in addition, it could even be employed in Heck reactions (89-96\% yield, 5 examples).63d

A single core palladacyclic azobenzene catalyst with CNCN chelation was successfully synthesized (Figure 2, B) and used successfully in Suzuki-Miyaura and Heck reactions. However, it was only moderately active (27-70\% yield, 4 examples) and required high temperatures that led to decomposition of the catalyst.63c

A symmetric bisazobenzene derivative was used as chelating ligand to obtain unsymmetric $C N N$ pincer palladacycles (Figure 2, C) that showed high turnover numbers (TONs) even under the harsh conditions of the Heck reaction (60-93\% yield, 9 examples, TONs up to 93000).63e

Phosphine-free Pd(II) complexes with 2,2'-bis(alkylamino)azobenzene ligands were obtained in good yields by reaction of the ligands with sodium tetrachloropalladate. In this work, the benzyl derivative (Figure 2, D) showed high catalytic activity in Suzuki-Miyaura and Heck reactions under mild conditions in the presence of air and moisture (65$93 \%$ yield, 22 examples). ${ }^{63 f}$

It should be noted that the photoswitchability of the azobenzenes in Figure 2 was not exploited.

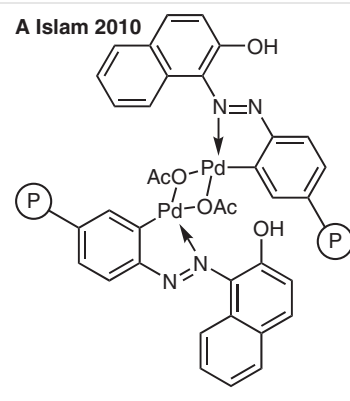

B Bulygina 2012
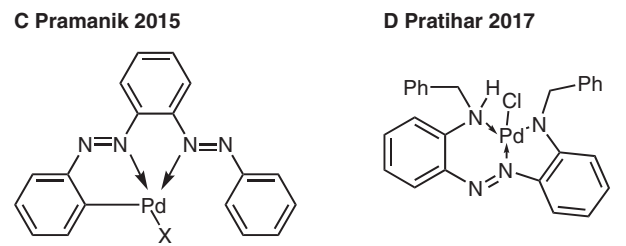

$\mathrm{X}=\mathrm{Cl}, \mathrm{Br}, \mathrm{I}, \mathrm{OAC}$

Figure 2 Evolution of palladium azo catalysts used in different crosscoupling reactions ${ }^{63 b, c, e, f}$

\section{Diazocines}

(Z)-11,12-Dihydrodibenzo[c,g][1,2]diazocines (diazocines) are ethylene-bridged azobenzenes that can be switched from their thermodynamic stable $(Z)$ - to the metastable $(E)$-isomer by using blue light at $\lambda \approx 370-400$

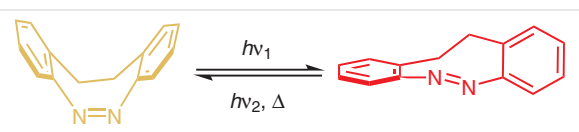

(Z)

(E)

Figure 3 Structure and isomerization of diazocine

$\mathrm{nm}$ and back from the $(E)$ - to the $(Z)$-isomer by green light at $\lambda \approx 480-550 \mathrm{~nm}$ (Figure 3). ${ }^{65}$

The switching properties of unsubstituted diazocines are different to unsubstituted azobenzenes. Diazocines show better resolution of absorption bands between the two isomeric states and switching is possible with light in the visible range. ${ }^{65}$ However, the substituents have a great impact on the switching properties of both azobenzenes and diazocines. For example, tetra-ortho-chlorinated azobenzenes can be switched to $(Z)$ at $\lambda \approx 560 \mathrm{~nm}$, which exceeds the redshift of regular diazocines. Amino substituents on diazocines have also been shown to reduce the separation of the absorption bands yielding low amounts of $(E)$ isomers (25-30\%). ${ }^{66}$ The synthesis of diazocines is more demanding compared to azobenzenes, which is why only few applications have been reported to date. ${ }^{65,67}$

\subsection{Synthesis}

The key step in any diazocine synthesis is the cyclization to form the diazene moiety. This has been performed by reduction of 2,2'-dinitrobibenzyls, ${ }^{65,67,68}$ or the oxidation of 2,2'-ethylenedianilines (Figure 4). ${ }^{69}$

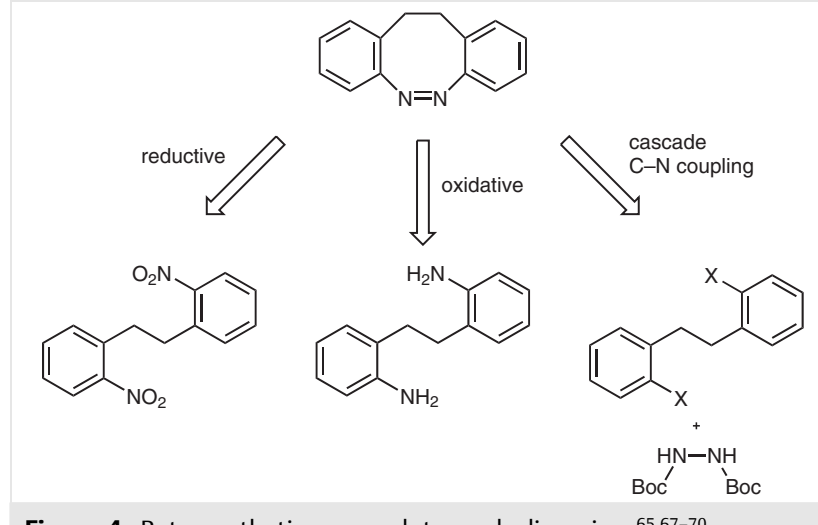

Figure 4 Retrosynthetic approach towards diazocines ${ }^{65,67-70}$

A novel route involving a cross-coupling reaction has been introduced by connecting the $\mathrm{C}-\mathrm{N}$ bond instead of the $\mathrm{N}-\mathrm{N}$ bond (Scheme 26). ${ }^{70}$ The diazocine ring in this route is formed via consecutive cross-coupling reactions between a 2,2'-dihalobibenzyl and di-tert-butyl hydrazodicarboxylate. $^{70}$ 


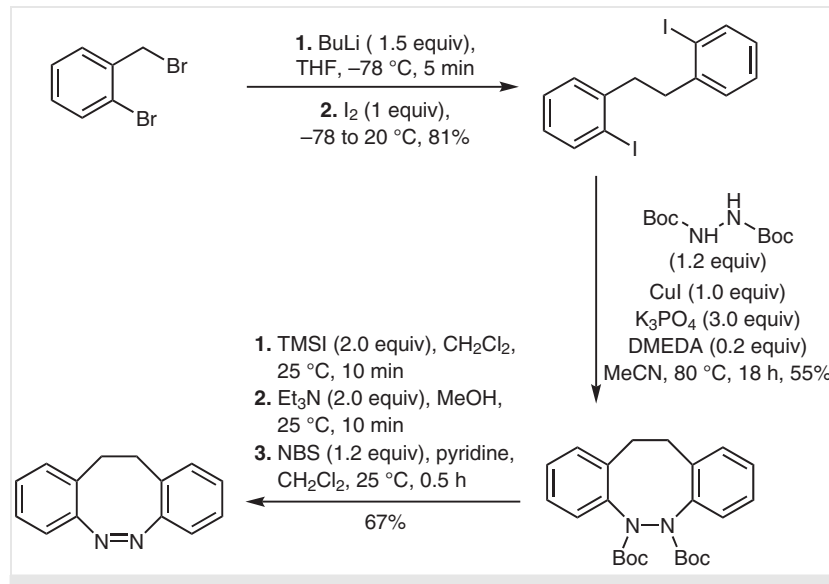

Scheme 26 Synthesis of diazocine through cross-coupling reaction ${ }^{70}$

\subsection{Cross-Coupling Reactions}

To date there are only a few reports of palladium-catalyzed cross-coupling reactions of diazocines. Therefore, a comparison with cross-coupling reactions of azobenzenes is, at present, of little informative value. Due to the different electronic and geometric structures of azobenzenes and diazocines, a different reactivity can be expected (as the lone pairs in diazocine are not aligned with the $\pi$-systems of the aromatic rings). At first glance the yields seem to be lower for cross-coupling reactions on diazocines, but this might be misleading since it is unknown if the reaction conditions were optimized. The Heck reaction of an 8-substituted 3bromodiazocine with a glutamate derivative yielded diazocine ligands capable of light-controlling neural receptors (Scheme 27).67c

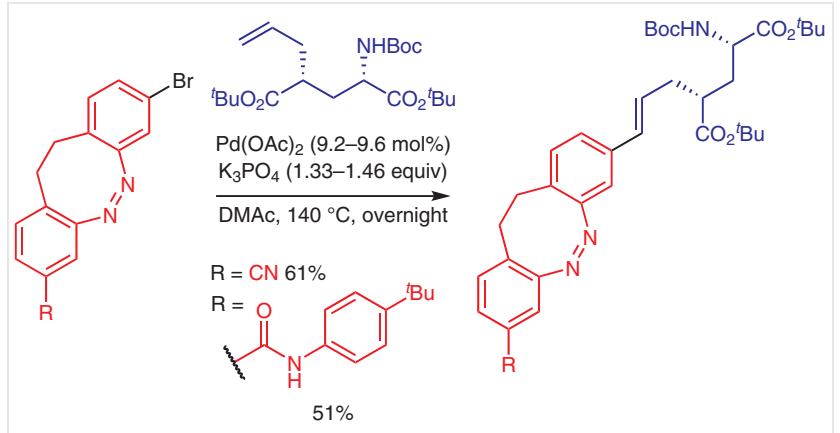

Scheme 27 Pd-catalyzed Heck coupling of diazocine derivatives ${ }^{67 c}$

A Buchwald-Hartwig coupling on 3-bromodiazocines with tert-butyl carbamates was successfully performed (Scheme 28, A). ${ }^{69 b}$ Furthermore, the coupling of benzophenone imine with bromodiazocines was reported (Scheme $28, \mathrm{~B}) .{ }^{71}$ The synthesis of a diazocine with turn-on fluorescence was achieved by the coupling of 3,8-dibromodiazocine with diphenylamine (Scheme $28, \mathrm{C}$ ). ${ }^{72}$

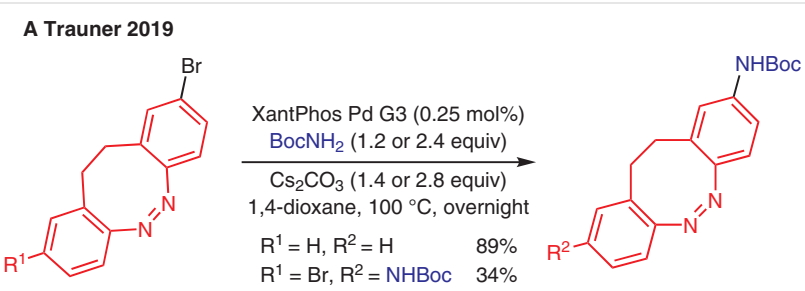

B Yan 2018<smiles>Brc1ccc2c(c1)CCc1ccccc1N=N2</smiles>

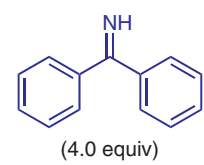

1. $\mathrm{Pd}(\mathrm{OAc})_{2}(6.0 \mathrm{~mol} \%)$, $\operatorname{BINAP}(9.0 \mathrm{~mol} \%)$

$\mathrm{Cs}_{2} \mathrm{CO}_{3}$ (1.4 equiv), THF, reflux, overnight 2. Workup $27 \%$

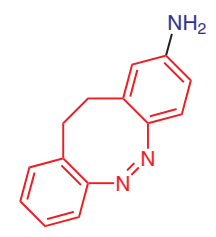

C Chen 2019
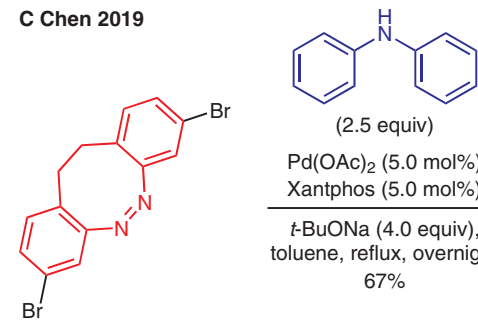

$\mathrm{Pd}(\mathrm{OAc})_{2}$ (5.0 mol\%) Xantphos (5.0 mol\%)

$t$-BuONa (4.0 equiv), toluene, reflux, overnight $67 \%$

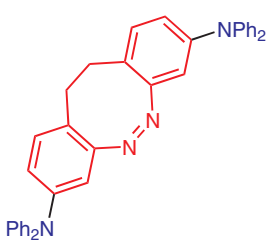

Scheme 28 Buchwald-Hartwig cross-coupling reactions of diazocine derivatives ${ }^{69 b, 71,72}$

Turn-on fluorescence diazocines were prepared by a Stille cross-coupling reaction (Scheme 29, A). ${ }^{72}$ Furthermore, it was possible to obtain a pyroglutamate diazocine derivative via the Stille cross-coupling reaction (Scheme 29, B). ${ }^{67 \mathrm{e}}$

\section{Conclusion}

Cross-coupling reactions have proved to be a powerful tool for the late-stage modification of both electrophilic and nucleophilic azobenzene derivatives, with palladium catalysis being most prevalent. The Suzuki-Miyaura and Sonogashira cross-coupling reactions are the most widely used. First examples of cross-coupling reactions catalyzed by other transition metals than palladium, such as nickel or cobalt, have been published thus broadening the scope of cross-coupling reactions towards new bond formations that are not possible with palladium catalysts. At present, the number of examples of the use of azobenzenes as formally electrophilic reactants is much greater than that for their use as formally nucleophilic reactants. Most likely, this does not reflect intrinsic problems with nucleophilic azobenzenes, but rather that their accessibility is limited at present 


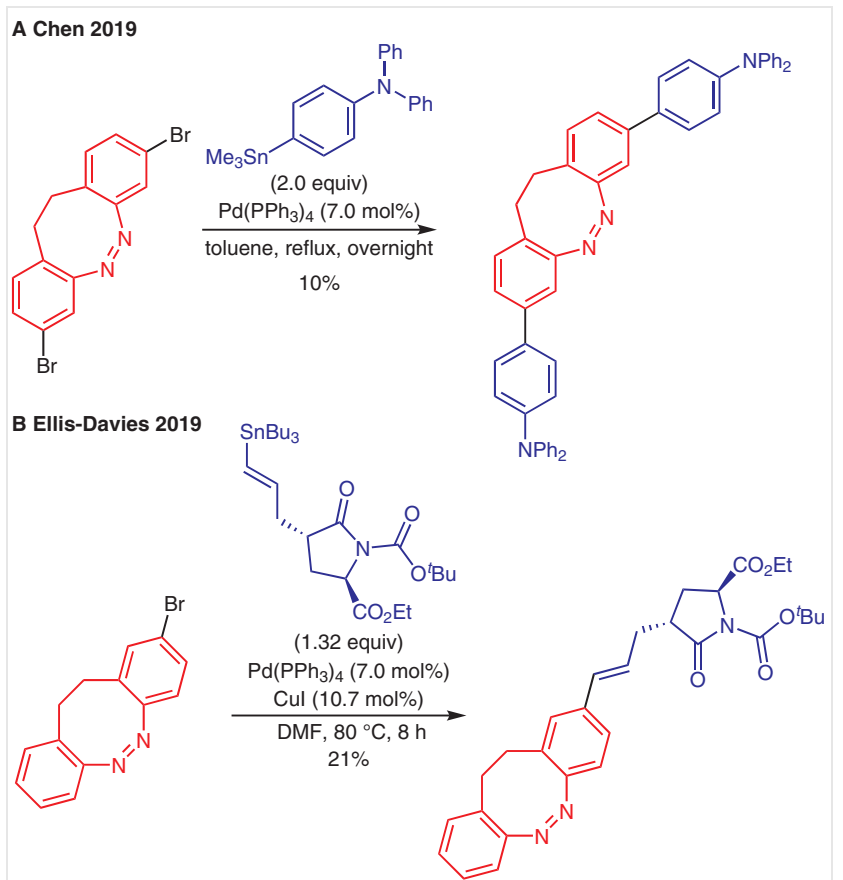

Scheme 29 Pd-catalyzed Stille cross-coupling reactions of diazocine derivatives ${ }^{67 e, 72}$

and requires more research. The reported yields do not significantly differ for cross-coupling reactions with azobenzene as formally the electrophilic or as nucleophilic component. However, due to the difficulties in the synthesis of nucleophilic azobenzene derivatives, cross-coupling reactions involving formally electrophilic azobenzene derivatives are favored. Normally, cross-coupling reactions with formally nucleophilic azobenzene derivatives are only used if the as nucleophilic coupling partner in the reaction of electrophilic azobenzene derivative cannot be synthesized. Most reported examples of cross-coupling reactions involving azobenzene derivatives employ the para-isomer; there are few examples of the use of the meta- or even the ortho-isomer. In fact, some groups specifically pointed out that cross-coupling reactions on ortho-azobenzene derivatives were unsuccessful. So cross-coupling reactions in the ortho-position of azobenzenes are almost, but not completely, unknown. The different reaction behavior of ortho-azobenzene derivatives in comparison to their corresponding meta- and para-isomers can be attributed to the nature of the diazenyl group; due to the adjacent lone electron pair on the nitrogen atoms, the diazenyl group can interact with substituents in the ortho-position. For example, ortho-halogenated precursors that are easily accessible can be directly lithiated because the ortho-lithiated species is significant stabilized by $\mathrm{N} \rightarrow$ Li coordination. Although the diazenyl group has this directing and stabilizing effect also for transition metal insertions, only very few examples of metalated ortho-azobenzenes exist. C-H Activation is, therefore, a valuable al- ternative especially for the modification of ortho-azobenzenes. In almost all examples of $\mathrm{C}-\mathrm{H}$ activation on azobenzenes, the ortho-position was functionalized. Here, the use of palladium complexes as catalysts was not as dominant as for the cross-coupling reactions. Another promising field is the use of complexed azobenzene derivatives acting as ligands or promotors for catalysts. New synthetic procedures for the preparation of diazocines means that they are accessible in good yields. Therefore, further functionalization possibilities through cross-coupling reactions can now be explored.

\section{Funding Information}

A.S. and S.S. thank the German Research Foundation (DFG) for the financial support within the priority program SPP 2100 'Soft Material Robotic Systems', Subproject STA1195/5-1, 'Insect feet inspired concepts soft touch grippers with dynamically adjustable grip strength'.

\section{Acknowledgment}

The authors would like to thank Dr. Anne Heitmann for proofreading.

\section{References}

(1) Merino, E.; Ribagorda, M. Beilstein J. Org. Chem. 2012, 8, 1071.

(2) Hartley, G. S. Nature 1937, 140, 281.

(3) (a) Brown, C. J. Acta Crystallogr. 1966, 21, 146. (b) Mostad, A.; Rømming, C. Acta Chem. Scand. 1971, 25, 3561.

(4) Hartley, G. S.; Le Fèvre, R. J. W. J. Chem. Soc. 1939, 531

(5) Åstrand, P.-O.; Ramanujam, P. S.; Hvilsted, S.; Bak, K. L.; Sauer, S. P. A. J. Am. Chem. Soc. 2000, 122, 3482.

(6) (a) Cheben, P.; del Monte, F.; Worsfold, D. J.; Carlsson, D. J.; Grover, C. P.; Mackenzie, J. D. Nature 2000, 408, 64. (b) Ikeda, T.; Sasaki, T.; Ichimura, K. Nature 1993, 361, 428.

(7) (a) Merino, E. Chem. Soc. Rev. 2011, 40, 3835. (b) Léonard, E.; Mangin, F.; Villette, C.; Billamboz, M.; Len, C. Catal. Sci. Technol. 2016, 6, 379.

(8) (a) Nystrom, R. F.; Brown, W. G. J. Am. Chem. Soc. 1948, 70, 3738. (b) Khan, A.; Hecht, S. Chem. Commun. 2006, 4764.

(9) (a) Pausacker, K. H. J. Chem. Soc. 1953, 1989. (b) Lu, W.; Xi, C. Tetrahedron Lett. 2008, 49, 4011. (c) Ma, H.; Li, W.; Wang, J.; Xiao, G.; Gong, Y.; Qi, C.; Feng, Y.; Li, X.; Bao, Z.; Cao, W.; Sun, Q.; Veaceslav, C.; Wang, F.; Lei, Z. Tetrahedron 2012, 68, 8358. (d) Zhang, C.; Jiao, N. Angew. Chem. Int. Ed. 2010, 49, 6174.

(10) (a) Ibne-Rasa, K. M.; Lauro, C. G.; Edwards, J. O. J. Am. Chem. Soc. 1963, 85, 1165. (b) Davey, M. H.; Lee, V. Y.; Miller, R. D.; Marks, T. J. J. Org. Chem. 1999, 64, 4976.

(11) (a) Cohen, T.; Lewarchik, R. J.; Tarino, J. Z. J. Am. Chem. Soc. 1974, 96, 7753. (b) Shine, H. J.; Zmuda, H.; Kwart, H.; Horgan, A. G.; Brechbiel, M. J. Am. Chem. Soc. 1982, 104, 5181.

(12) Matsui, M.; Iwata, Y.; Kato, T.; Shibata, K. Dyes Pigm. 1988, 9, 109.

(13) (a) Katritzky, A. R.; Wu, J.; Verin, S. V. Synthesis 1995, 651. (b) Farhadi, S.; Sepahvand, S. J. Mol. Catal. A: Chem. 2010, 318, 75. (c) Alberti, A.; Bedogni, N.; Benaglia, M.; Leardini, R.; Nanni, D.; Pedulli, G. F.; Tundo, A.; Zanardi, G. J. Org. Chem. 1992, 57, 607. 
(14) (a) Burns, J.; McCombie, H.; Scarborough, H. A. J. Chem. Soc. 1928, 2928. (b) Robertson, P. W.; Hitchings, T. R.; Will, G. M. J. Chem. Soc. 1950, 808. (c) Fahey, D. R. J. Organomet. Chem. 1971, 27, 283. (d) Fahey, D. R. J. Chem. Soc. D 1970, 417. (e) Konrad, D. B.; Frank, J. A.; Trauner, D. Chem. Eur. J. 2016, 22, 4364. (f) Li, J.; Cong, W.; Gao, Z.; Zhang, J.; Yang, H.; Jiang, G. Org. Biomol. Chem. 2018, 16, 3479.

(15) (a) Han, M. R.; Hashizume, D.; Hara, M. Acta Crystallogr., Sect. E 2006, 62, o3001. (b) Bléger, D.; Ciesielski, A.; Samorì, P.; Hecht, S. Chem. Eur. J. 2010, 16, 14256. (c) De Jesús, M.; Larios-López, L.; Rodríguez-González, R. J.; Navarro-Rodríguez, D. J. Mol. Liq. 2016, 222, 1031. (d) Torres-Rocha, O. L.; Larios-López, L.; Rodríguez-González, R. J.; Felix-Serrano, I.; Navarro-Rodríguez, D. J. Mol. Liq. 2017, 225, 251. (e) Huang, W.; Lee, S.-K.; Sung, Y. M.; Peng, F.; Yin, B.; Ma, M.; Chen, B.; Liu, S.; Kirk, S. R.; Kim, D.; Song, J. Chem. Eur. J. 2015, 21, 15328. (f) Heitmann, G.; Dommaschk, M.; Löw, R.; Herges, R. Org. Lett. 2016, 18, 5228. (g) Yin, B.; Kim, T.; Zhou, M.; Huang, W.; Kim, D.; Song, J. Org. Lett. 2017, 19, 2654. (h) Nguyen, T.-T.-T.; Turp, D.; Wang, D.; Nolscher, B.; Laquai, F.; Mullen, K. J. Am. Chem. Soc. 2011, 133, 11194. (i) Izumi, A.; Teraguchi, M.; Nomura, R.; Masuda, T. Macromolecules 2000, 33, 5347. (j) Li, L.; He, F.; Wang, X.; Ma, N.; Li, L. ACS Appl. Mater. Interfaces 2012, 4, 4927. (k) Cheng, H. L.; Tang, M. T.; Tuchinda, W.; Enomoto, K.; Chiba, A.; Saito, Y.; Kamiya, T.; Sugimoto, M.; Saeki, A.; Sakurai, T.; Omichi, M.; Sakamaki, D.; Seki, S. Adv. Mater. Interfaces 2015, 2, 1400450. (l) Zhao, R.; Zhan, X.; Yao, L.; Chen, Q.; Xie, Z.; Ma, Y. Macromol. Rapid Commun. 2016, 37, 610. (m) Huang, C.-W.; Ji, W.-Y.; Kuo, S.-W. Polym. Chem. 2018, 9, 2813. (n) Wang, K.; Yin, L.; Miu, T.; Liu, M.; Zhao, Y.; Chen, Y.; Zhou, N.; Zhang, W.; Zhu, X. Mater. Chem. Front. 2018, 2, 1112. (o) Otaki, M.; Kumai, R.; Goto, H. J. Polym. Sci., Part A: Polym. Chem. 2019, 57, 1756. (p) Wang, Z.; Müller, K.; Valášek, M.; Grosjean, S.; Bräse, S.; Wöll, C.; Mayor, M.; Heinke, L. J. Phys. Chem. C 2018, 122, 19044. (q) Ma, X.; Qu, D.; Ji, F.; Wang, Q.; Zhu, L.; Xu, Y.; Tian, H. Chem. Commun. 2007, 1409. (r) Ma, X.; Wang, Q.; Tian, H. Tetrahedron Lett. 2007, 48, 7112. (s) Reuter, R.; Wegner, H. A. Beilstein J. Org. Chem. 2012, 8 , 877.

(16) Chen, Y.; Li, C.; Xu, X.; Liu, M.; He, Y.; Murtaza, I.; Zhang, D.; Yao, C.; Wang, Y.; Meng, H. ACS Appl. Mater. Interfaces 2017, 9, 7305.

(17) Han, M.; Norikane, Y.; Onda, K.; Matsuzawa, Y.; Yoshida, M.; Hara, M. New J. Chem. 2010, 34, 2892.

(18) Qu, D. H.; Wang, Q. C.; Ma, X.; Tian, H. Chem. Eur. J. 2005, 11, 5929.

(19) Köhl, I.; Lüning, U. Synthesis 2014, 46, 2376.

(20) (a) Bryant-Friedrich, A. C.; Neidlein, R. Helv. Chim. Acta 1997, 80, 1639. (b) Yu, B.-C.; Shirai, Y.; Tour, J. M. Tetrahedron 2006, 62, 10303. (c) Zarwell, S.; Rück-Braun, K. Tetrahedron Lett. 2008, 49, 4020. (d) Zeitouny, J.; Aurisicchio, C.; Bonifazi, D.; De Zorzi, R.; Geremia, S.; Bonini, M.; Palma, C. A.; Samorì, P.; Listorti, A.; Belbakra, A.; Armaroli, N. J. Mater. Chem. 2009, 19, 4715. (e) Itoi, H.; Kambe, T.; Kano, N.; Kawashima, T. Inorg. Chim. Acta 2012 , 381, 117. (f) Jaumann, E. A.; Steinwand, S.; Klenik, S.; Plackmeyer, J.; Bats, J. W.; Wachtveitl, J.; Prisner, T. F. Phys. Chem. Chem. Phys. 2017, 19, 17263. (g) Koumura, N.; Kudo, M.; Tamaoki, N. Langmuir 2004, 20, 9897. (h) Moreno, C.; Arnanz, A.; Medina, R.-M.; Macazaga, M.-J.; Pascual, M.; García-Frutos, E. M.; Martínez-Gimeno, E.; Marcos, M.-L. Organometallics 2015, 34, 2971. (i) Zhao, Y.; Li, K.; Zhang, Y.; Zhao, Y.; Miao, Z. Mol. Cryst. Liq. Cryst. 2017, 650, 7. (j) Huo, X.; Xu, Q. P.; Miao, Z. Appl. Mech. Mater. 2014, 584-586, 1705. (k) Okano, K.; Tsutsumi, O.; Shishido, A.; Ikeda, T. J. Am. Chem. Soc. 2006, 128, 15368. (l) Kuciauskas, D.; Porsch, M. J.; Pakalnis, S.; Lott, K. M.; Wright,
M. E. J. Phys. Chem. B 2003, 107, 1559. (m) Humphrey, J. L.; Lott, K. M.; Wright, M. E.; Kuciauskas, D. J. Phys. Chem. B 2005, 109, 21496. (n) Shen, D.; Pan, Z.; Xu, H.; Cheng, S.; Zhu, X.; Fan, L. Chin. J. Chem. 2010, 28, 1279. (o) Ansari, M.; Bera, R.; Mondal, S.; Das, N. ACS Omega 2019, 4, 9383. (p) Iba, S.; Ishida, T.; Sanda, F. Polym. Bull. 2020, 77, 1121. (q) Nath, I.; Chakraborty, J.; Khan, A.; Arshad, M. N.; Azum, N.; Rab, M. A.; Asiri, A. M.; Alamry, K. A.; Verpoort, F. J. Catal. 2019, 377, 183. (r) Mohamed Ahmed, M. S.; Mori, A. Tetrahedron 2004, 60, 9977. (s) Liao, L.-X.; Stellacci, F.; McGrath, D. V. J. Am. Chem. Soc. 2004, 126, 2181. (t) CasasSolvas, J. M.; Vargas-Berenguel, A. Tetrahedron Lett. 2008, 49, 6778.

(21) Shirtcliff, L. D.; Weakley, T. J. R.; Haley, M. M.; Köhler, F.; Herges, R. J. Org. Chem. 2004, 69, 6979.

(22) Heindl, A. H.; Wegner, H. A. Beilstein J. Org. Chem. 2020, 16, 22.

(23) Liu, Y.; Yang, W.; Liu, H. Chem. Eur. J. 2015, 21, 4731.

(24) Jiang, C.; Yang, W.; Liu, H. Russ. Chem. Bull. 2016, 65, 1076.

(25) Izumi, A.; Teraguchi, M.; Nomura, R.; Masuda, T. J. Polym. Sci., Part A: Polym. Chem. 2000, 38, 1057.

(26) Quandt, G.; Höfner, G.; Pabel, J.; Dine, J.; Eder, M.; Wanner, K. T. J. Med. Chem. 2014, 57, 6809.

(27) Izumi, A.; Nomura, R.; Masuda, T. Macromolecules 2001, 34, 4342.

(28) Gøgsig, T. M.; Kleimark, J.; Nilsson Lill, S. O.; Korsager, S.; Lindhardt, A. T.; Norrby, P. O.; Skrydstrup, T. J. Am. Chem. Soc. 2012, 134, 443 .

(29) Xu, X.-D.; Zhang, J.; Chen, L.-J.; Zhao, X.-L.; Wang, D.-X.; Yang, H.-B. Chem. Eur. J. 2012, 18, 1659.

(30) Al-Balushi, R. A.; Haque, A.; Jayapal, M.; Al-Suti, M. K.; Husband, J.; Khan, M. S.; Skelton, J. M.; Molloy, K. C.; Raithby, P. R. Inorg. Chem. 2016, 55, 10955.

(31) Zhao, R.; Han, J.; Huang, M.; Liu, F.; Wang, L.; Ma, Y. Macromol. Rapid Commun. 2017, 38, 1700274.

(32) Ghosh, T.; Maity, P.; Kundu, D.; Ranu, B. C. New J. Chem. 2016, 40, 9556.

(33) Strueben, J.; Gates, P. J.; Staubitz, A. J. Org. Chem. 2014, 79, 1719.

(34) Strueben, J.; Lipfert, M.; Springer, J.-O.; Gould, C. A.; Gates, P. J.; Sönnichsen, F. D.; Staubitz, A. Chem. Eur. J. 2015, 21, 11165.

(35) Garlichs-Zschoche, F. A.; Dötz, K. H. Organometallics 2007, 26, 4535.

(36) Harvey, J. H.; Butler, B. K.; Trauner, D. Tetrahedron Lett. 2007, 48, 1661.

(37) Zhao, F.; Grubert, L.; Hecht, S.; Bléger, D. Chem. Commun. 2017, $53,3323$.

(38) (a) Hansen, M. J.; Lerch, M. M.; Szymanski, W.; Feringa, B. L. Angew. Chem. Int. Ed. 2016, 55, 13514. (b) Hierrezuelo, J.; Rico, R.; Valpuesta, M.; Díaz, A.; López-Romero, J. M.; Rutkis, M.; Kreigberga, J.; Kampars, V.; Algarra, M. Tetrahedron 2013, 69, 3465.

(39) Miao, Z.; Li, Y.; Zhang, X. Appl. Mech. Mater. 2014, 584-586, 1673.

(40) (a) Yu, Z.; Hecht, S. Angew. Chem. Int. Ed. 2011, 50, 1640. (b) Yu, Z.; Hecht, S. Chem. Eur. J. 2012, 18, 10519.

(41) (a) Sogawa, H.; Shiotsuki, M.; Matsuoka, H.; Sanda, F. Macromolecules 2011, 44, 3338. (b) Sogawa, H.; Shiotsuki, M.; Sanda, F. Macromolecules 2013, 46, 4378. (c) Okano, K.; Shishido, A.; Ikeda, T. Adv. Mater. 2006, 18, 523.

(42) Gerstel, P.; Klumpp, S.; Hennrich, F.; Poschlad, A.; Meded, V.; Blasco, E.; Wenzel, W.; Kappes, M. M.; Barner-Kowollik, C. ACS Macro Lett. 2014, 3, 10.

(43) Zhang, Y.; Chen, S. RSC Adv. 2018, 8, 37348.

(44) Kanbara, T.; Oshima, M.; Imayasu, T.; Hasegawa, K. Macromolecules 1998, 31, 8725. 
(45) Honma, A.; Kanbara, T.; Hasegawa, K. Mol. Cryst. Liq. Cryst. 2000, $345,125$.

(46) Chun, C.; Kim, M.-J.; Vak, D.; Kim, D. Y.J. Mater. Chem. 2003, 13, 2904.

(47) Chun, C.; Ghim, J.; Kim, M.-J.; Kim, D. Y. J. Polym. Sci., Part A: Polym. Chem. 2005, 43, 3525.

(48) Chen, X.; Chang, G. Chin. J. Chem. 2009, 27, 2093.

(49) Sakano, T.; Horie, M.; Osakada, K.; Nakao, H. Eur. J. Inorg. Chem. 2005, 644 .

(50) Bahrenburg, J.; Sievers, C. M.; Schönborn, J. B.; Hartke, B.; Renth, F.; Temps, F.; Näther, C.; Sönnichsen, F. D. Photochem. Photobiol. Sci. 2013, 12, 511.

(51) Zhang, Y.; Zhang, Q.; Pei, S.; Wang, Y.; Zhang, H.; Jiang, Z. High Perform. Polym. 2014, 26, 946.

(52) (a) Li, H.; Li, P.; Wang, L. Org. Lett. 2013, 15, 620. (b) Khatun, N.; Modi, A.; Ali, W.; Patel, B. K. J. Org. Chem. 2015, 80, 9662. (c) Li, M.; Ye, Y. ChemCatChem 2015, 7, 4137. (d) Hong, G.; Aruma, A. N.; Zhu, X.; Wu, S.; Wang, L. Synthesis 2016, 48, 1147. (e) Yong, W. S.; Park, S.; Yun, H.; Lee, P. H. Adv. Synth. Catal. 2016, 358, 1958. (f) Fu, X.; Wei, Z.; Xia, C.; Shen, C.; Xu, J.; Yang, Y.; Wang, K.; Zhang, P. Catal. Lett. 2017, 147, 400. (g) Gu, N.; Sun, S.; Cheng, J. Tetrahedron Lett. 2018, 59, 1069.

(53) (a) Wang, H.; Yu, Y.; Hong, X.; Tan, Q.; Xu, B. J. Org. Chem. 2014, 79, 3279. (b) Fu, T.; Yang, J.; Sun, H.; Zhang, C.; Xiang, H.; Zhou, X. Asian J. Org. Chem. 2018, 7, 1844.

(54) Li, J.; Zhou, H.; Zhang, J.; Yang, H.; Jiang, G. Chem. Commun. 2016, 52, 9589.

(55) (a) Cai, S.; Lin, S.; Yi, X.; Xi, C. J. Org. Chem. 2017, 82, 512. (b) Oh, Y.; Han, S. H.; Mishra, N. K.; De, U.; Lee, J.; Kim, H. S.; Jung, Y. H.; Kim, I. S. Eur. J. Org. Chem. 2017, 6265. (c) Zhu, J.; Sun, S.; Cheng, J. Tetrahedron Lett. 2018, 59, 2284.

(56) Deng, H.; Li, H.; Wang, L. Org. Lett. 2016, 18, 3110.

(57) Bruce, M. I.; Iqbal, M. Z.; Stone, F. G. A. Chem. Commun. 1970, 1325.

(58) Li, G.; Ma, X.; Jia, C.; Han, Q.; Wang, Y.; Wang, J.; Yu, L.; Yang, S. Chem. Commun. 2017, 53, 1261.

(59) (a) Borah, G.; Borah, P.; Patel, P. Org. Biomol. Chem. 2017, 15, 3854. (b) Hande, A. E.; Muniraj, N.; Prabhu, K. R. ChemistrySelect 2017, 2, 5965. (c) Muniraj, N.; Prabhu, K. R. J. Org. Chem. 2017, $82,6913$.

(60) Borah, G.; Patel, P. Org. Biomol. Chem. 2019, 17, 2554.

(61) Li, G.; Chen, X.; Lv, X.; Jia, C.; Gao, P.; Wang, Y.; Yang, S. Sci. China: Chem. 2018, 61, 660.
(62) Kato, T.; Kuriyama, S.; Nakajima, K.; Nishibayashi, Y. Chem. Asian J. 2019, 14, 2097.

(63) (a) Lee, K.-E.; Jeon, H.-T.; Han, S.-Y.; Ham, J.; Kim, Y.-J.; Lee, S. W. Dalton Trans. 2009, 6578. (b) Islam, S. M.; Mondal, P.; Roy, A. S.; Mondal, S.; Hossain, D. Tetrahedron Lett. 2010, 51, 2067. (c) Bulygina, L. A.; Khrushcheva, N. S.; Peregudova, S. M.; Sokolov, V. I. Russ. Chem. Bull. 2012, 61, 1998. (d) Priyadarshani, N.; Suriboot, J.; Bergbreiter, D. E. Green Chem. 2013, 15, 1361. (e) Roy, S.; Pramanik, S.; Ghorui, T.; Pramanik, K. RSC Adv. 2015, 5, 22544. (f) Pratihar, J. L.; Mandal, P.; Lin, C.-H.; Lai, C. K.; Mal, D. Polyhedron 2017, 135, 224.

(64) Alder, M. J.; Cross, W. I.; Flower, K. R.; Pritchard, R. G. J. Organomet. Chem. 1999, 590, 123.

(65) Siewertsen, R.; Neumann, H.; Buchheim-Stehn, B.; Herges, R.; Näther, C.; Renth, F.; Temps, F. J. Am. Chem. Soc. 2009, 131, 15594.

(66) Moormann, W.; Langbehn, D.; Herges, R. Beilstein J. Org. Chem. 2019, 15, 727.

(67) (a) Joshi, D. K.; Mitchell, M. J.; Bruce, D.; Lough, A. J.; Yan, H. Tetrahedron 2012, 68, 8670. (b) Eljabu, F.; Dhruval, J.; Yan, H. Bioorg. Med. Chem. Lett. 2015, 25, 5594. (c) Cabré, G.; GarridoCharles, A.; González-Lafont, À.; Moormann, W.; Langbehn, D.; Egea, D.; Lluch, J. M.; Herges, R.; Alibés, R.; Busqué, F.; Gorostiza, P.; Hernando, J. Org. Lett. 2019, 21, 3780. (d) Trads, J. B.; Hüll, K.; Matsuura, B. S.; Laprell, L.; Fehrentz, T.; Görldt, N.; Kozek, K. A.; Weaver, C. D.; Klöcker, N.; Barber, D. M.; Trauner, D. Angew. Chem. Int. Ed. 2019, 58, 15421. (e) Thapaliya, E. R.; Zhao, J.; EllisDavies, G. C. R. ACS Chem. Neurosci. 2019, 10, 2481.

(68) (a) Tellkamp, T.; Shen, J.; Okamoto, Y.; Herges, R. Eur. J. Org. Chem. 2014, 5456. (b) Moormann, W.; Langbehn, D.; Herges, R. Synthesis 2017, 49, 3471. (c) Samanta, S.; Qin, C.; Lough, A. J.; Woolley, G. A. Angew. Chem. Int. Ed. 2012, 51, 6452. (d) Li, S.; Han, G.; Zhang, W. Macromolecules 2018, 51, 4290. (e) Deo, C.; Bogliotti, N.; Métivier, R.; Retailleau, P.; Xie, J. Chem. Eur.J. 2016, 22, 9092.

(69) (a) Wang, J.; He, J.; Zhi, C.; Luo, B.; Li, X.; Pan, Y.; Cao, X.; Gu, H. RSC Adv. 2014, 4, 16607. (b) Maier, M. S.; Hüll, K.; Reynders, M.; Matsuura, B. S.; Leippe, P.; Ko, T.; Schäffer, L.; Trauner, D. J. Am. Chem. Soc. 2019, 141, 17295.

(70) Li, S.; Eleya, N.; Staubitz, A. Org. Lett. 2020, 22, 1624.

(71) Jun, M.; Joshi, D. K.; Yalagala, R. S.; Vanloon, J.; Simionescu, R.; Lough, A. J.; Gordon, H. L.; Yan, H. ChemistrySelect 2018, 3, 2697.

(72) Zhu, Q.; Wang, S.; Chen, P. Org. Lett. 2019, 21, 4025. 